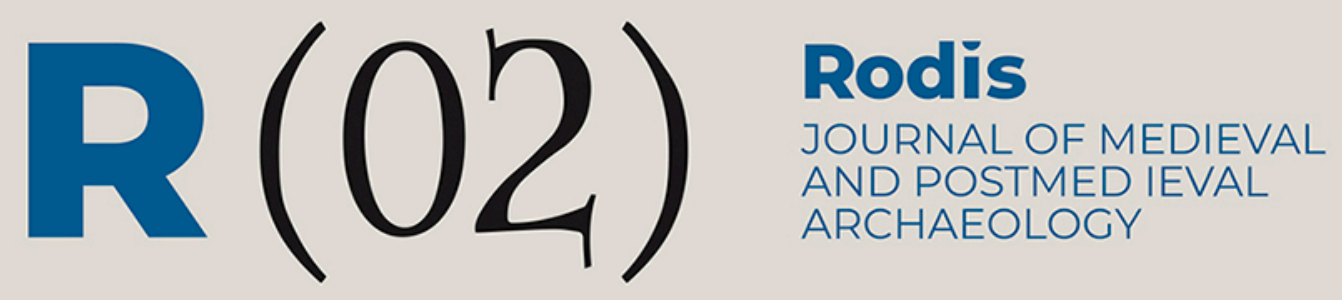

Infraestructures portuàries d'època medieval i moderna a la Mediterrània occidental

Medieval and modern harbour infrastructures in the western Mediterranean

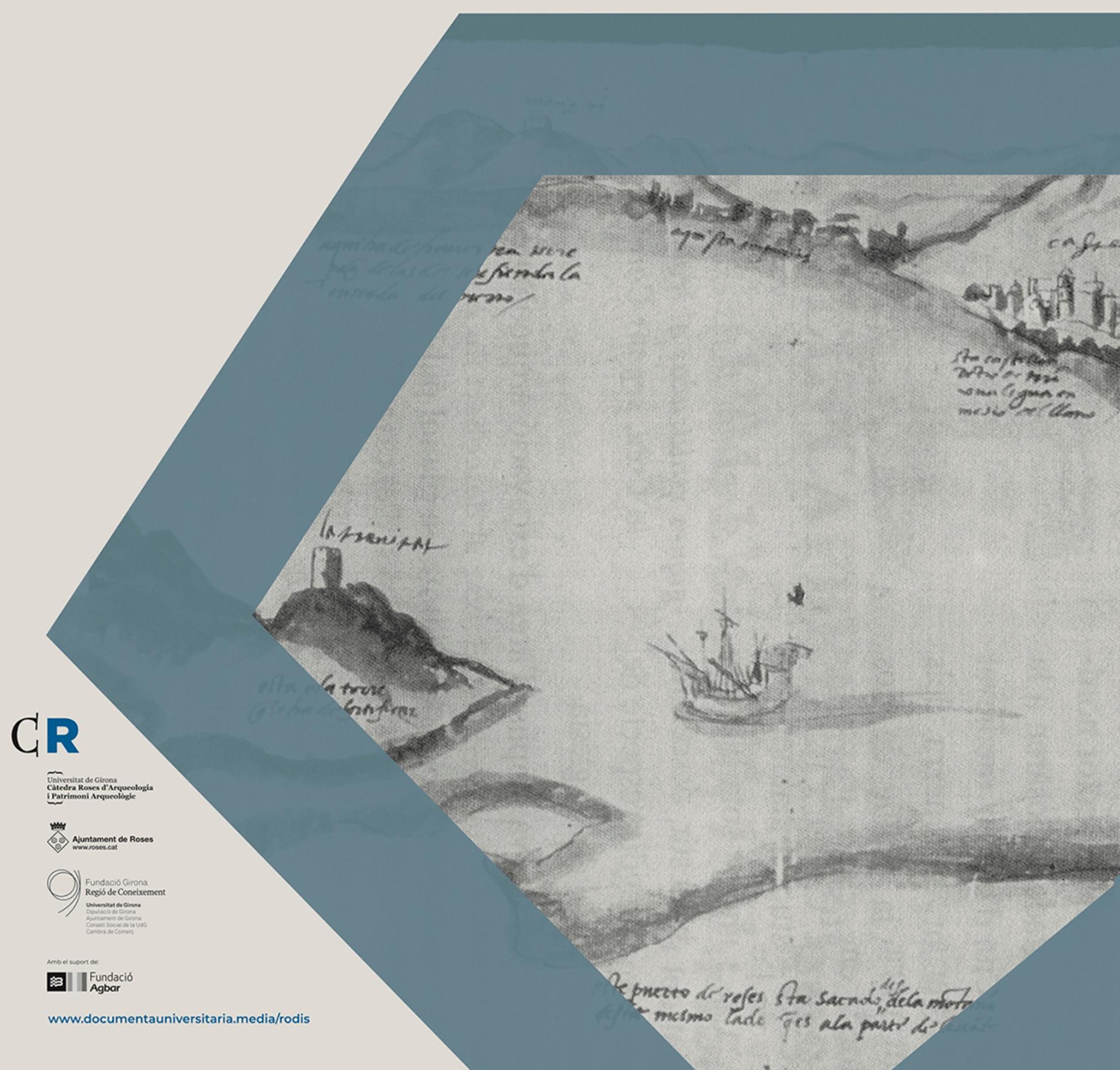


Rodis. Journal of Medieval and Post-Medieval Archaeology - 02

(c) Material editorial i organització / Editorial material and organization:

Universitat de Girona, Càtedra Roses d'Arqueologia i Patrimoni Arqueològic

(c) Continguts i figures / Content and figures: els autors / the authors

Equip editorial, objectius de la revista i instruccions per als autors i política editorial / Editoria team, magazine objectives and instructions for authors and editorial policy:

www.documentauniversitaria.media/rodis

Contacte / Contact:

Càtedra Roses d'Arqueologia i Patrimoni Arqueològic

cat.rosesarqueologia@udg.edu

Universitat de Girona

Plaça Ferrater Mora, 1

17071 Girona

Tel. 972458290

ISSN: 2604-6679 


\section{ÍNDEX / INDEX}

Presentació

Presentation

Josep Burch

DOSSIER

INFRAESTRUCTURES PORTUÀRIES D'ÈPOCA MEDIEVAL I MODERNA A LA MEDITERRÀNIA OCCIDENTAL

MEDIEVAL AND MODERN HARBOUR INFRASTRUCTURES

IN THE WESTERN MEDITERRANEAN

La Torre de la Trinitat i la pesca de la tonyina (Roses, 1350-1550)

Trinity Tower and tuna fishing (Roses, 1350-1550)

Marcel Pujol i Hamelink

Els ports de Barcelona, Sant Feliu de Guíxols i Roses a la baixa edat mitjana: una comparativa

The harbours of Barcelona, Sant Feliu de Guíxols and Roses in the late middle ages: a comparison

Marcel Pujol i Hamelink

Strutture portuali, architetture e forme urbane medievali tra XI e XIV secolo. Lo spazio tirrenico toscano, la Sardegna, le isole Port structures, architecture and medieval urban forms between the 11th and 14th centuries. The tyrrhenian tuscan space, Sardinia, the islands

Marco Cadinu

Evolució del front marítim de la zona portuària de Barcelona de la tardoantiguitat a l'edat moderna

Evolution of the seafront of the port area of Barcelona from the late antiquity to the modern age

Santiago Riera Mora, Ramon Julià Brugués, Carme Miró Alaix 
Building in the city. From archaeological markers to the historical reconstruction of the worksite. Some examples from medieval Rome La costruzione della città. Dai marcatori archeologici alla ricostruzione storica dell'opera. Alcuni esempi di Roma medievale

Nicoletta Giannini 


\title{
ELS PORTS DE BARCELONA, SANT FELIU DE GUIXXLS I ROSES A LA BAIXA EDAT MITJANA: UNA COMPARATIVA
}

THE HARBOURS OF BARCELONA, SANT FELIU DE GUÍXOLS AND ROSES IN THE LATE MIDDLE AGES: A COMPARISON

DOI: https://doi.org/10.33115/a/26046679/2_2

\author{
Marcel Pujol i Hamelink* \\ Escola Superior de Conservació i Restauració \\ de Béns Culturals de Catalunya \\ Codi Orcid: 0000-0003-2876-8233
}

Paraules clau

Port, medieval, Barcelona, Sant Feliu de Guíxols, Roses

Key words

Harbour, medieval, Barcelona, Sant Feliu de Guíxols, Roses

El treball forma part dels projectes de recerca: "Tripulacions, armaments, construcció naval i navegació a la Mediterrània medieval", HAR2013-48433-C2-1-P (Ministeri d'Economia i Competitivitat), i "La Corona catalanoaragonesa, I'Islam i el món mediterrani”, CAIMM-2014-SGR1559 (Departament d'Economia i Coneixement, Generalitat de Catalunya), tots dos dirigits por la Dra. Roser Salicrú (Institut d'Història Medieval-CSIC, Barcelona). 


\section{Resum}

La recerca planteja una comparació entre els ports de Barcelona, Sant Feliu de Guíxols i Roses, tenint en compte les seves característiques geomorfològiques i geoestratègiques, el seu paper com a ports comtals, la connexió amb les principals vies comercials terrestres i marítimes i la seva interrelació amb els diferents ports de la Costa de Llevant catalana. Tot i ser Barcelona el principal port de Catalunya, els altres dos destacaren en alguns aspectes gràcies a les seves condicions nàutiques i a les seves infraestructures portuàries.

\section{Abstract}

In this research we compare the harbours of Barcelona, Sant Feliu de Guíxols and Roses, taking into consideration their geomorphological and geostrategic features, their role as county harbours, their connection with the main land and maritime trade routes and their link with the different ports of the Eastern Catalan coast. Even though Barcelona was the main port of the Catalan coast, the other two had same advantages thanks to their nautical characteristics and their harbour infrastructures. 


\section{ELS PORTS DE BARCELONA, SANT FELIU DE GUÍXOLS I ROSES A LA BAIXA EDAT MITJANA: UNA COMPARATIVA}

La Mediterrània ha estat històricament un espai de frontera i de comunicació alhora. Per aquesta raó no es pot entendre la creació i l'existència dels comtats catalans de la Costa de Llevant sense la presència d'una sèrie de ports marítims. Aquests ports que van permetre utilitzar el mar com a via de comunicació entre els comtats i més enllà; és a dir, cap a qualsevol port de la Mediterrània d'una manera fàcil, ràpida i poc costosa, al contrari de la tradicional via terrestre.

Per entendre quins foren aquests ports, el primer que hem de fer és definir què és un port. D'una manera ben simple, un port es pot definir com el lloc de contacte d'un medi marítim i un de terrestre, $i$ on, alhora, es produeix la transferència de persones i béns materials (i també béns immaterials, com els coneixements i les malalties) d'un a l'altre. També es podria considerar un port el lloc de contacte i transferència d'un medi marítim a un de fluvial o lacustre, o d'un de terrestre cap a un de fluvial o lacustre. Per tant, també podem arribar a distingir entre ports marítims i ports fluvials. ${ }^{\top}$

Ara bé, qualsevol punt de la costa no serveix com a port. El lloc en concret que s'acaba triant per a aquesta funció sempre es veu condicionat per raons geomorfològiques i geogràfiques.

Els condicionants geomorfològics tenen a veure amb les característiques físiques del lloc que es triarà com a port. Una de les principals característiques és que estigui situat en una cala ben a resguard dels temporals de vent i de mar, i també protegit contra els corrents i els atacs enemics. Per tant, és important que disposi d'una protecció natural. D’altres característiques essencials són: que tingui una fondària adient per ancorar-hi les embarcacions sense perill d'embarrancar; una platja de sorra que faciliti la càrrega i descàrrega de mercaderies, o bé treure en terra les embarcacions per ser reparades o construïdes (amb un espai prou ampli per a les barques de pesca — de $6 \mathrm{~m}$ de llargada de roda a roda- o les naus — de 40 m de llargada-, a banda d'un desnivell d'uns 15 a $20^{\circ}$ que en faciliti la varada); un puig que serveixi per construir-hi una torre per a la defensa del port, per vigilar el mar i que, a més la funció dissuasiva per als enemics, sigui

1 També existeixen els ports fluvials com a ports de connexió del trànsit marítim i fluvial. Les embarcacions marítimes poden remuntar el riu fins a un punt on el calat ja no ho permet, o bé perquè troben una barrera, com per exemple un pont, que no els permet seguir més amunt. En aquest punt se sol formar un port on les mercaderies es descarreguen en terra o directament d'una embarcació marítima a una de fluvial, o a l'inrevés. L'exemple més proper el tenim a Tortosa, on les embarcacions marítimes, fins i tot les més grans, com les naus, podien remuntar l'Ebre des del delta fins a aquesta població. En aquell punt trobaven la barrera del Pont de Barques, que obligava a descarregar les mercaderies. Si havien de continuar més amunt, cap a Saragossa o Lleida, les embarcacions fluvials s'encarregaven de transportar-les. 
un element visible i indicador que el port existeix —un far- capaç d'enviar missatges al port o ciutat; i finalment, disposar del que tot port ha de tenir: aigua potable, tan necessària per a l'avituallament de les tripulacions, mitjançant pous, fonts, rieres o rius.

Els condicionants geogràfics tenen a veure amb la seva relació respecte a les vies comercials, tant marítimes com terrestres, fluvials i lacustres, a més de la seva connexió o proximitat amb el centre econòmic, polític o administratiu més proper i el seu hinterland, o bé amb la seva funció militar o pesquera. Per tant, la tria del lloc i el grau d'activitat portuària poden acabar sent una decisió política, per la qual cosa d'aquest tipus de condicionants en podem dir també condicionants geoestratègics.

Per tant, un port no s'ha d'entendre com un lloc on hi ha la presència de molls i espigons, drassanes, grues, construcció i reparació d'embarcacions, etc., sinó que pot ser simplement una platja utilitzada com a lloc de càrrega i descàrrega de mercaderies (Diaz et al. 1986, 2; Igual 2014, 110). Les infraestructures portuàries construïdes no són res més que complements artificials a un indret triat com a port i construits per a la seva millora, tenint en compte en primer lloc els condicionants geomorfològics i geogràfics.

Tots aquests condicionants van intervenir en la creació dels ports i la seva evolució durant l'edat mitjana. Sovint, per diverses raons (econòmiques, polítiques i tecnològiques), els ports van guanyar o perdre importància o activitat, per la qual cosa moltes vegades van haver de buscar solucions que redrecessin la situació. El grau d'activitat d'un port no depèn solament de factors humans, aplicats de manera conscient o involuntària, sinó que també es poden veure afectats per possibles canvis en la dinàmica dels corrents litorals i en l'aportació de sediments fluvials i marítims.

La nostra intenció pretén comparar els principals ports de la Costa de Llevant catalana, és a dir, els ports de la Catalunya Vella, i ens haurem de remuntar fins al moment en què es crearen els comtats per trobar l'origen dels que anem a estudiar.

\section{LA CATALUNYA COMTAL}

L'imperi carolingi, després de conquerir Narbona (760), seguí amb la seva expansió cap al sud, fins arribar a Barcelona, procés durant el qual va crear tota una sèrie d'entitats administratives que coneixem com a comtats. Deixant de banda els comtats de l'interior, i seguint la costa a partir de Narbona, es creà el comtat del Rosselló (760), el comtat d'Empúries, el comtat de Girona (785) i el de Barcelona (801), fins que quedà establerta la frontera entre l'Imperi i AlÀndalus en l'àrea del Garraf-Penedès durant més de 300 anys, fins a la conquesta de Tarragona (1116) i Tortosa (1148).

Si observem els diferents comtats, podem veure com la seva capital política, administrativa i econòmica es troba en molts casos a l'interior, com és el cas de 
Perpinyà i Girona. Al comtat d'Empúries, durant els primers segles d'aquell període, la capital es trobà en aquesta ciutat, fins que en el segle XI es traslladà a l'interior, cap a Castelló d'Empúries. ${ }^{2}$ La quarta capital comtal, Barcelona, es troba al litoral.

Així, pràcticament totes les capitals comtals - Perpinyà, Girona i Barcelonas'establiren a la via Francisca (l'antiga Via Augusta), excepte Empúries i la nova capital emporitana, Castelló d'Empúries, que es trobaven totalment descentrades respecte a aquesta ruta. A l'àrea de l'Empordà, el principal eix viari nord-sud passava fora dels límits del comtat d'Empúries, seguia per Figueres (comtat de Besalú) i anava cap a la Jonquera, per on es dirigia cap al Rosselló pel coll de Panissars. Existia una branca secundària que passava per Peralada - capital del vescomtat homònim (1078) - i continuava cap al Rosselló pel coll de Banyuls.

D'aquesta manera tots aquests comtats es trobaven situats en el pas de dues grans vies de comunicació - una de marítima i una de terrestre- que anaven de nord a sud i confluien a Barcelona (fig. 1). En la resta dels comtats, les capitals eren interiors (Perpinyà, Castelló d'Empúries i Girona), i es veien obligades a enllaçar amb la via marítima mitjançant un camí que les connectés amb un port (Cotlliure, Roses, Sant Feliu de Guíxols). Així es crea el binomi capital-port, i la connexió entre la via Francisca i la marítima, en què l'excepció serà Barcelona, que era alhora capital i port, i punt de connexió de les dues principals vies de comunicació marítima i terrestre.

Barcelona no només jugava amb l'avantatge de ser capital i port, sinó que la seva posició a la frontera entre els mons cristià i musulmà li permetia dominar el comerç amb aquest darrer, i per tant tenia accés als productes nord-africans i orientals, a més del botí aconseguit a les ràtzies a la zona fronterera, la participació amb contingents de tropes mercenàries en els conflictes interns d'Al-Àndalus i el cobrament de les pàries. Es convertí en la principal ciutat del conjunt de comtats catalans, el principal centre econòmic i demogràfic, en el qual el comte de Barcelona acabà rebent el vassallatge de la resta de comtes, i gradualment, mitjançant enllaços matrimonials, anà adquirint el títol comtal de pràcticament tots els comtats. El d'Empúries va ser el darrer que s'hi incorporà, l'any 1402.

\section{LA COSTA DE LLEVANT}

Si observem el mapa de la Costa de Llevant es pot veure clarament que, tenint en compte les distàncies entre les capitals comtals i els seus ports, hi ha una certa relació entre Barcelona i Sant Feliu de Guíxols, i d'aquesta població amb Cotlliure. Queden separades entre si per 100-110 km, gairebé els mateixos que

2 Segurament el canvi de capitalitat al comtat d'Empúries va tenir lloc a mitjan segle XI, en temps del comte Ponç I (1040-1078), atès que Empúries fou pràcticament devastada l'any 935 en l'atac de l'estol musulmà d'Ibn Abu Hamama, i que el 9 de setembre de 1064 és consagrada solemnement la nova església de Castelló d'Empúries amb la presència dels comtes d'Empúries, de Barcelona i de Besalú. Tres anys després el comte Ponç I es declarava vassall del comte de Barcelona (Balañà 1981, 134). 


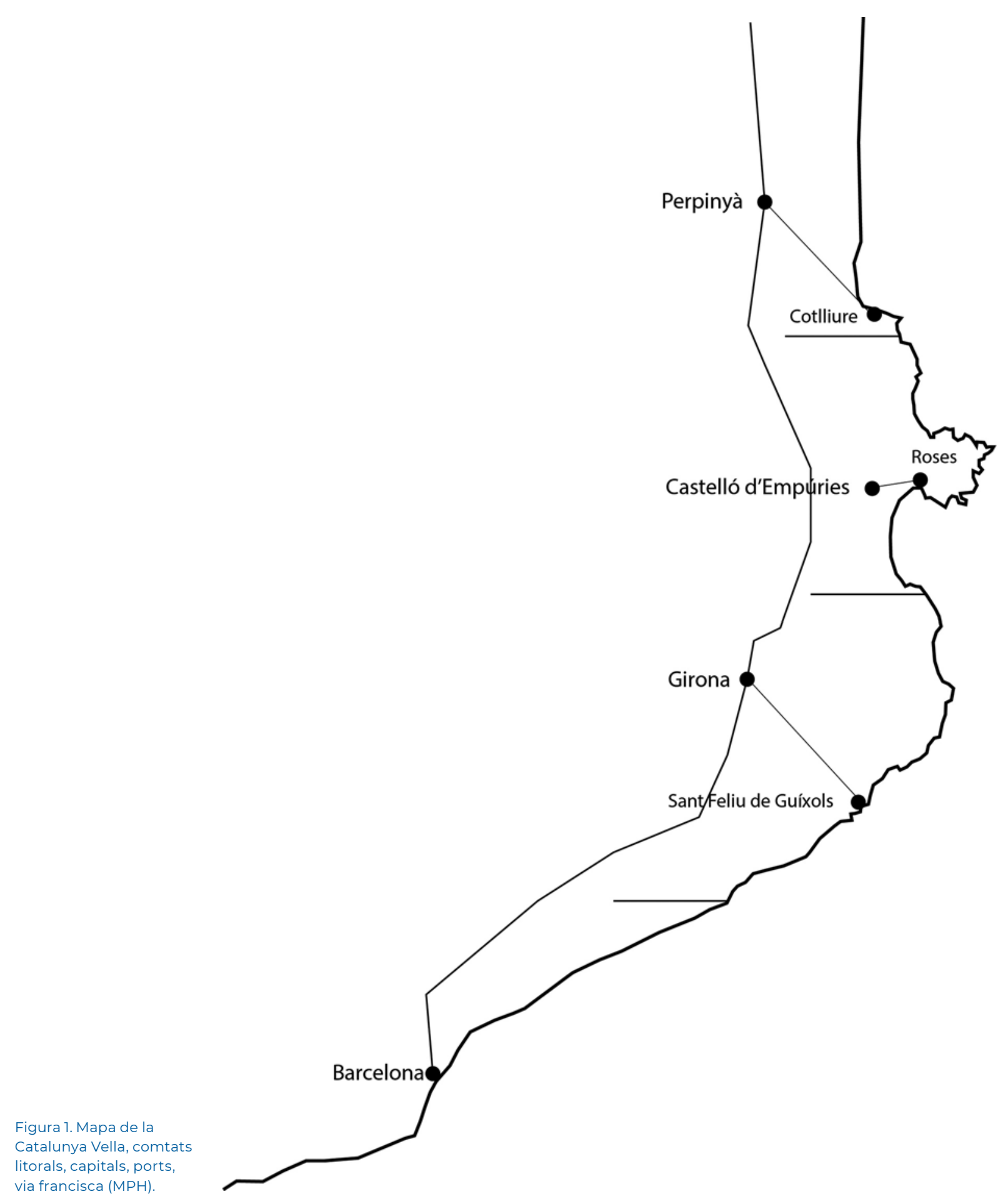


les seves capitals establertes a la via Francisca: 100 km entre Barcelona i Girona i $100 \mathrm{~km}$ entre Girona i Perpinyà. La situació no és la mateixa per a Castelló d'Empúries ni el seu port. Roses es troba entre Sant Feliu de Guíxols i Cotlliure, gairebé a mig camí, i Castelló no només a mitja distància entre Perpinyà i Girona, sinó allunyada de la via Francisca, a uns $11 \mathrm{~km}$. Aquestes circumstàncies podrien ser una de les causes per les quals el port de Roses acabà quedant relegat a un segon o tercer rang en el sistema portuari català de la baixa edat mitjana. ${ }^{3}$

Un altre aspecte a comparar entre les capitals comtals i els seus ports és la demografia, la qual podem estudiar en molts casos gràcies als fogatges. Aquest impost, que es cobrava per foc o per casa, ens serveix per conèixer la quantitat de cases que hi havia en cada població. Multiplicant aquesta xifra per una mitjana de 4-5 persones per llar, podem arribar a obtenir el nombre total d'habitants. Hem utilitzat els fogatges de dos períodes: el situat en plena gran crisi de mitjan segle XIV i el de finals del XV, moment en què Catalunya s'estava recuperant demogràficament. En el primer, dels anys $1360-1365,{ }^{4}$ tenim el conjunt PerpinyàCotlliure amb 15.830 habitants, Girona-Sant Feliu de Guíxols amb 10.700 i Barcelona amb 32.840. De Castelló d'Empúries i Roses no tenim dades. En el segon fogatge, dels anys 1470-1497 (Iglésies 1991), tot i la pèrdua d'habitants, notable en alguns casos, es manté la diferència de pes demogràfic, semblant al del fogatge precedent: Perpinyà-Cotlliure amb 9.710 habitants, Castelló-Roses amb 2.970, Girona-Sant Feliu de Guíxols amb 6.530 i Barcelona amb 30.830. És evident que el pes demogràfic emporità era molt inferior a la resta, només un 10 $\%$ del de Barcelona, un $30 \%$ del de Perpinyà i Cotlliure i el $50 \%$ del de Girona i Sant Feliu.

Barcelona, Sant Feliu de Guíxols, Roses i Cotlliure no eren els únics ports, però eren els més importants, tot i la voluntat reial d'afavorir els seus propis ports en detriment dels de les altres senyories. Dona una clara indicació sobre els ports importants del segle xiv l'acord pres a les Corts Generals de Montsó l'any 1363, que habilità com a ports carregadors i descarregadors Cotlliure, Roses, Torroella de Montgrí, Palamós, Sant Feliu de Guíxols i Barcelona per a la costa de Llevant. Tots van ser considerats «portus» excepte el de Torroella, que era designat com a "gradus", perquè segurament el punt on tocaven platja era el grau del Ter, situat més o menys on avui dia es troba l'Estartit. El 1365 s'afegiren Canet i Sant Llorenç com a desembarcadors a la platja del Rosselló, davant de Perpinyà (Salicrú 2003).

3 Sembla que el sistema portuari català queda definit a finals del segle XII, moment en el qual Catalunya (i per extensió la Corona d'Aragó) comença a intervenir amb força en el comerç marítim mediterrani, en deslliurar-se del suport naval de Gènova o Pisa (Orvietani 2001). En el segle següent es converteix en una nova potència marítima amb la conquesta de Mallorca, el 1228-1229, rol que consolida amb la Guerra de Sicília i la Croada contra Catalunya, entre els anys 1282 i 1285.

4 Es calcula que a Barcelona, abans de l'esclat de la crisi demogràfica del segle XIV $(1333,1348)$ hi vivien 40.000 persones. Tot i la crisi, l'àrea que més ràpidament es recuperà de la ciutat fou el Quarter de Mar: 1363, 2.032 focs; 1378, 2.167 focs; 1399, 2.319 focs, un augment considerable fins a la Guerra Civil del 1462 (Garcia 2007, 41-42 ). Fogatge 1360-1365 (Batlle 1968; Iglésies 1962). 


\section{BARCELONA}

La primera imatge coneguda de la ciutat de Barcelona correspon a una vista de la ciutat des de Montjuïc realitzada per Jan Cornelisz Vermeyen l'any 1535, ${ }^{5}$ seguida de les dues vistes d'Antoine van den Wijngaerde, de l'any 1563.

La primera vista de Wijngaerde (fig. 2) presenta la ciutat des del mar, tal com la veien mariners, pescadors i tota la gent que hi arribava o se n'allunyava per mar. Era una visió de la ciutat totalment inimaginable i radicalment diferent respecte a la que tenia un pagès, pastor o traginer que arribava a la ciutat per terra, des del Pla de Barcelona. En aquesta vista marítima hi ha tota una sèrie d'elements que s'haurien d'anar eliminant per tal d'imaginar-nos l'aspecte que deuria tenir al segle xIv, començant per eliminar la muralla amb baluards i amb una sola porta al mar, aixecada durant la primera meitat del segle Xvi, i que es troba en primer terme; tot seguit, caldria eliminar la muralla que té tota una llarga sèrie de portes i que fou aixecada a finals del s. XIV i durant gran part del Xv. D'aquesta manera ens quedaríem amb una vista de Barcelona de la segona meitat del Xiv, en la qual la ciutat es mostrava al mar, sense cap impediment físic, sense cap muralla que la defensés o la tapés, amb tots els principals edificis establerts en tota la façana marítima i amb activitat a la platja, estesa per tot el seu litoral.

La construcció de la muralla de mar no només tapà la façana marítima, sinó que amb la construcció d'una sola porta (el Portal de Mar, projecte de Gian Battista

Figura 2. Vista d'Antoine

van den Wijngaerde

(1563), Barcelona des

del mar.

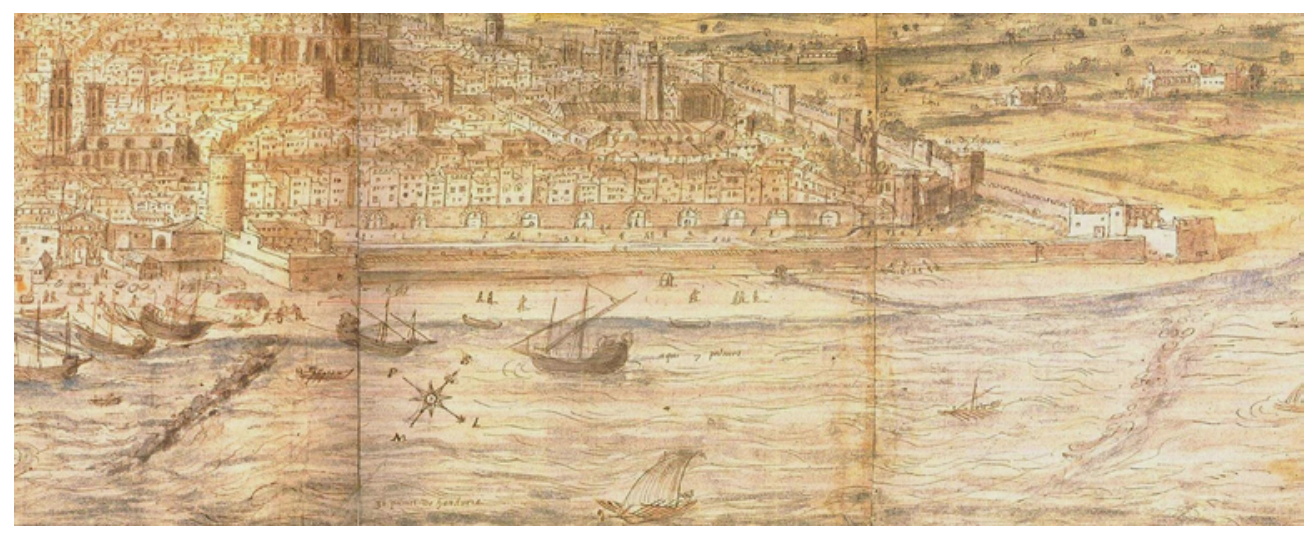

5 Aquesta imatge es troba publicada al Civitates Orbis Terrarum (1572), però es tracta d'un dibuix realitzat per Vermeyen en ocasió de l'expedició de Tunis de Carles I l'any 1535 (Horn 1989). 
Calvi de l'any 1554) es concentrà gairebé tota l'activitat litoral en aquest punt. Hem d'entendre la Barcelona medieval com una ciutat emmurallada pel costat de terra i oberta pel seu costat de mar.

La construcció de la muralla de mar, tant la baixmedieval com la renaixentista, implica un canvi sobretot visual i de la concentració de l'activitat portuària. Hi ha una sèrie de dates que considerem fites cronològiques de l'evolució de la façana marítima i del port de Barcelona. ${ }^{6}$

La primera se situa en l'any 1207, quan Pere el Catòlic decideix urbanitzar el litoral, l'espai que s'havia guanyat al mar, gràcies a l'aportació de sediments marins i fluvials i a la dessecació de part dels estanys litorals. La franja que es pretenia urbanitzar es dividí en tres zones: al nord, fins al rec Comtal, per a la canonja (al cap de poc aquesta zona va ser traspassada al financer Guillem Durfort); al sud, fins a la riera del Cagalell, per a Bernat Simó; ${ }^{7}$ i la zona del centre se la reservà el comte-rei, atès que hi tenia la drassana, els alfòndecs reials i s'hi concentrava també l'activitat mercantil (i altres serveis bàsics com els forns i el maell) i, per tant, també l'activitat fiscal.

La drassana era el lloc on el poder comtal construïa i guardava les seves embarcacions militars - les galeres-, que podia ser simplement un pati delimitat per un mur amb una o més portes encarades al mar. Al seu interior hi podia haver botigues o magatzems on es guardaven les veles, eixàrcia, armament i altres objectes de caire naval i bèllic. La construcció civil, d'embarcacions de pesca i de comerç, es feia directament a la platja, normalment allà on el mestre d'aixa tenia la seva botiga i escar. La drassana barcelonina serà eixamplada l'any 1243, segurament per la necessitat de guardar-hi més galeres al seu interior, per la qual cosa Jaume I ordenà l'enderrocament de botigues situades a l'est i prohibí construir-hi més cases i botigues en aquest indret. Es va dessecar la Llacuna, i es va esclarissar l'àrea on l'any 1369 hi havia «les proes de les galeres velles» (Cubeles 2014, 84-85). ${ }^{8}$ Es delimità així de manera clara el domini reial sobre aquesta àrea i els seus usos: militar i comercial.

La segona data se situa a l'any 1283-1285. Enmig del conflicte per Sicília i de la Croada contra Catalunya, la necessitat de disposar d'un estol de galeres

6 Per conèixer millor la façana marítima de Barcelona i el seu port segueixen essent imprescindibles els treballs de Cabestany-Sobrequés (1972), Cubeles $(2003,2014)$ Estrada $(2004,2008)$ i Soberón $(2012,2014)$.

7 A Bernat Simó: «totam illam placiam et arenale quod est de portali de la Derasana Barchinone usque ad rivam qui dicitur Cagalell et usque ad ripam maris cum tota mediante parietis de la Derasana ad ripam maris», amb la condició que per una banda hi hagués un carrer prou ample que permetés el pas de les moles que es feien a Montjuïc, i per altra un espai gran a la banda de platja on poder descarregar les mercaderies. El 1210 el rei autoritza a Durfort construir un forn (el de la Pescateria) a l'espai comprès «de Lacuna usque ad darassanam nec de foro usque ad mare» (Ortí 2000, 112-114, 215, notes 248, 256 i 508; Cubeles, Puig 2003, 54; Cubeles 2014, 82).

8 El document que parla de les proes de les galeres velles data de l'any 1369, i fa referència a la construcció de la muralla: «E que sie continuat lo dit mur prenent daguén anant dreta via tro devant les prohas de les galeras velles qui són prop la pascateria, e aquí devant les dites prohas de les galeras al cap del mur qui aquí serà, sie feta I altre torra closa [la Torre Nova]. E en lo mig del dit pati de les lles torres sie feta una altre torra oberta a part de dins, el mig de la qual sie fet I portal per eixir a mar. Item hi sie fet I altre portal en loch convinent, los quals II portals sien semblants a aquell portal qui és devant lo carrer dels fusters, los quals portals puxen servir a metre y traure les barques en temps de fortuna, e per exida dels habitants en aquella partida» (Cubeles 2014, 84-85). Realment és un misteri què són aquestes proes de galeres velles. Tant podien ser galeres que estaven arraconades per velles com galeres enemigues preses en batalles de finals del segle XIII o primera meitat del XIV, o simplement eren una mena de trofeu, com es feia a l'Antiguitat amb els esperons de les galeres preses als enemics, exposant-les en un mur o bé al capdamunt d'un pilar. 
n'augmentà la producció, tant a Barcelona com a bona part de la resta de ports catalans. No creiem que l'ordre reial tingués a veure amb la construcció - atès que si no hi havia espai dins la drassana per construir-les es podien construir a la platja - sinó la necessitat de tenir un lloc on emmagatzemar-les. Pere el Gran decideix construir una nova drassana al sud de la ciutat. Aquesta es construirà més enllà del perímetre urbà, que estava delimitat al nord pel convent de Santa Clara (1237) i al sud pel de Sant Francesc (1229), allà on havia existit l'antic hospital de Sant Nicolau, una façana urbana de 1.500 metres de longitud, a la qual s'havia d'afegir al sud la rambla i la Drassana Nova. La quantitat de galeres construïdes els anys previs a la conquesta de Sicília, a més de les que foren preses als enemics i l'arribada de l'estol sicilià (1282-1285), s'havien d'emmagatzemar i reparar a la nova drassana.

La Drassana Vella fou cedida a la ciutat, i durant uns decennis es mantingué com a lloc de construcció i emmagatzematge de les galeres construïdes pel Consell de la Ciutat, fins que es va canviar l'ús de l'espai.

Entre els anys 1358 i 1368 es comença a aixecar la muralla de mar, en la qual s'obriren moltes portes en tot el tram del barri de la Ribera, fet que seguí facilitant el trànsit de persones, mercaderies i peix entre la ciutat i el port, i evità que la defensa es convertís en un mur opac i clos.

E1 1378, la tercera data, és l'any en què el Consell de Cent s'integra, juntament amb la Diputació del General, en la gestió de la Drassana Nova o drassana reial, aportant capital per ampliar-les, cobrir les seves naus i construir galeres. A canvi, es va permetre el canvi d'ús i cessió definitiva de la Drassana Vella a la ciutat, la qual reconvertirà tot aquest espai en una àrea amb una funció exclusivament comercial i fiscal (Cubeles, Puig 2003, 59). Fou el punt de partida per a la gran remodelació urbanística que experimentà amb la construcció (i/o renovació) de la plaça i les voltes dels Encants, la nova Llotja (1380-1387), amb la duana i casa del Consolat de Mar, la casa de la Bolla o del General (1400), els Pallols, el porxo del Forment (1387-1389), l'Hala dels Draps (1441), la Torre Nova (1369), la font de l'Àngel o del Mar (1399-1402) i l'abeurador de la Llotja (fig. 3).

A finals del segle XIv el litoral de Barcelona es troba dividit en tres grans àrees funcionals: al sud, l'àrea militar a la Drassana Nova; al centre, l'àrea comercial $\mathrm{i}$, al nord, l'àrea pesquera. L'espai comprès entre la Drassana Nova i el port comercial es destina a magatzem de fusta i a la construcció naval, tant civil com militar. ${ }^{9}$ En aquesta àrea hi havia un espai adient per a la construcció de naus, en què les més grosses necessitaven uns $1.000 \mathrm{~m}^{2}$ per a l'escar, a més de lloc per al material de construcció, magatzems, càbries, etc., tot al voltant; mentre que una galera necessitava un escar de $350 \mathrm{~m}^{2}$, i una barca de pesca gran tan sols 40 .

9 Aquest és el lloc on es construïren bona part de les naus de Barcelona als segles XIV i xv. Per exemple, l'any 1456, la nau de Jaume Pertegàs es construí entre l'abeurador de la Llotja i la font de l'Àngel de la Fusteria. El dietari (Sans 1994) diu que la varada d'aquesta nau fou complexa i lenta: «prou penjats van a la forca pus tost que no feya ella a mar», perquè es tardaren 44 dies a varar-la. Una nau grossa podia fer més de $40 \mathrm{~m}$ de llargada, més de $10 \mathrm{~m}$ d'amplada, 3 cobertes i una alçada de 8-10 m, a més de l'alçada a proa i a popa dels dos castells, als quals s'ha de sumar encara l'alçada dels tres arbres, pes i un volum enorme. El port d'aquests grans vaixells mercants podia depassar les 1.000 tones (més de 2.000 botes). 


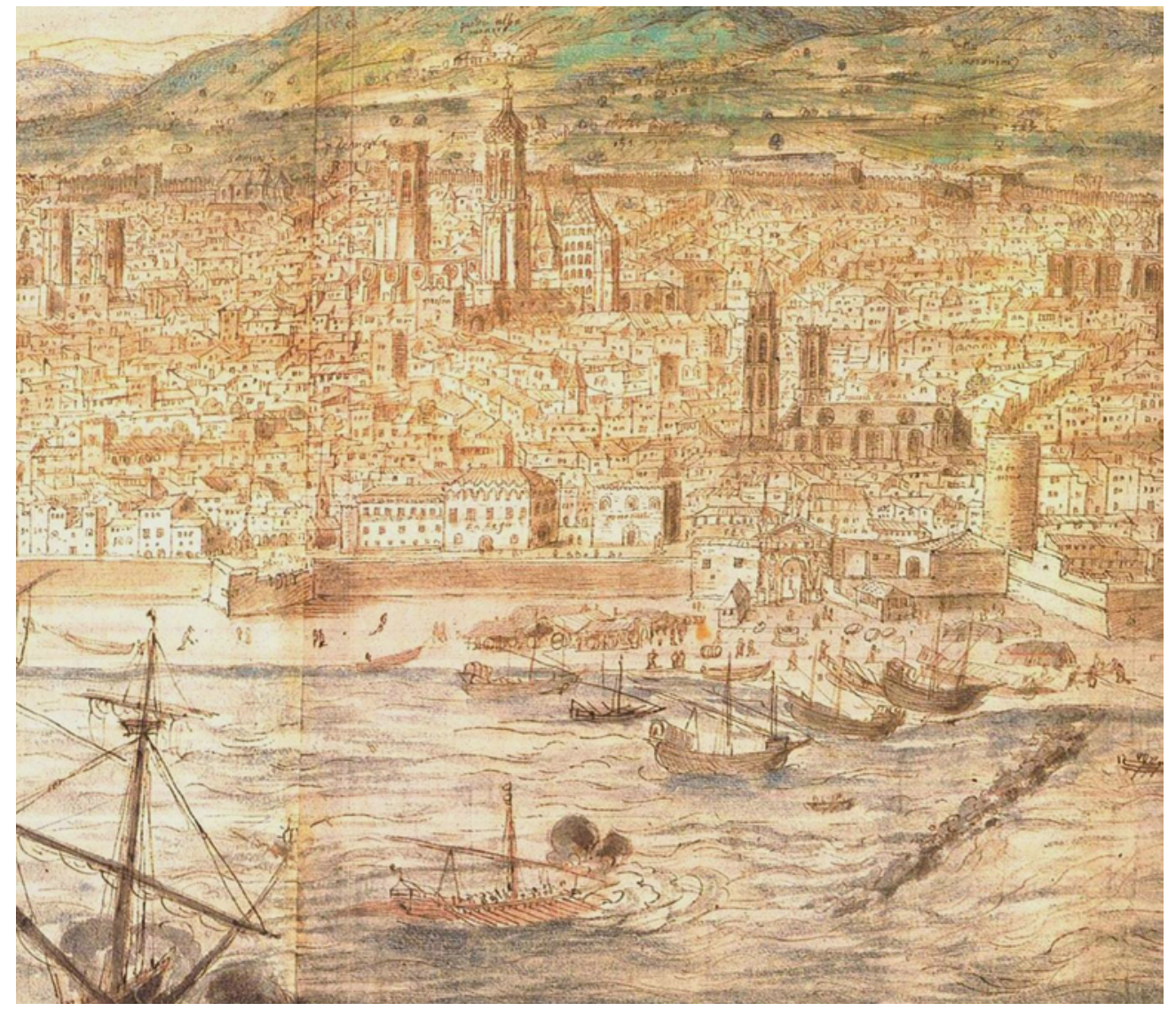

Figura 3. Detall de l'àrea comercial: edificis. Wijngaerde, 1563.

El port de Barcelona no només ocupava la franja litoral situada entre el convent de Santa Clara i la Drassana Nova, sinó que tenia algunes infraestructures més enllà del perímetre urbà, com la torre de Montjuïc al sud i la torre de Montgat al nord. En la segona vista de Barcelona realitzada per Wijngaerde (fig. 4), es pot observar en primer terme la torre de Montjuic, amb els tres pals al capdamunt, que servien per transmetre senyals a la ciutat (mitjançant la combinació i posició d'una vela a l'arbre central i de poms als arbres laterals).

Aquesta vista ens serveix també per visualitzar les àrees funcionals del port de Barcelona: en primer terme la Drassana Nova i, al davant, la presència d'un conjunt de galeres, empopades a la costa, mentre al centre de l'Arenal se situa el port comercial, amb la presència de magatzems, piles de mercaderies, un conjunt força gran d'embarcacions petites i mitjanes tocant terra $\mathrm{i}$ força moviment de persones, la majoria mariners, mercaders, bastaixos, pescadors i mestres d'aixa, entre d'altra gent de mar.

Es veu de forma clara que des del punt de vista geomorfològic el port de Barcelona tenia moltes carències. És cert que hi havia una llarga platja de sorra que permetia l'acostament de les embarcacions petites i mitjanes per carregar i descarregar les seves mercaderies, per varar i treure-les en terra si feia mal 
Figura 4. Vista d'Antoine van den Wijngaerde (1563), Barcelona des de Montjuic.
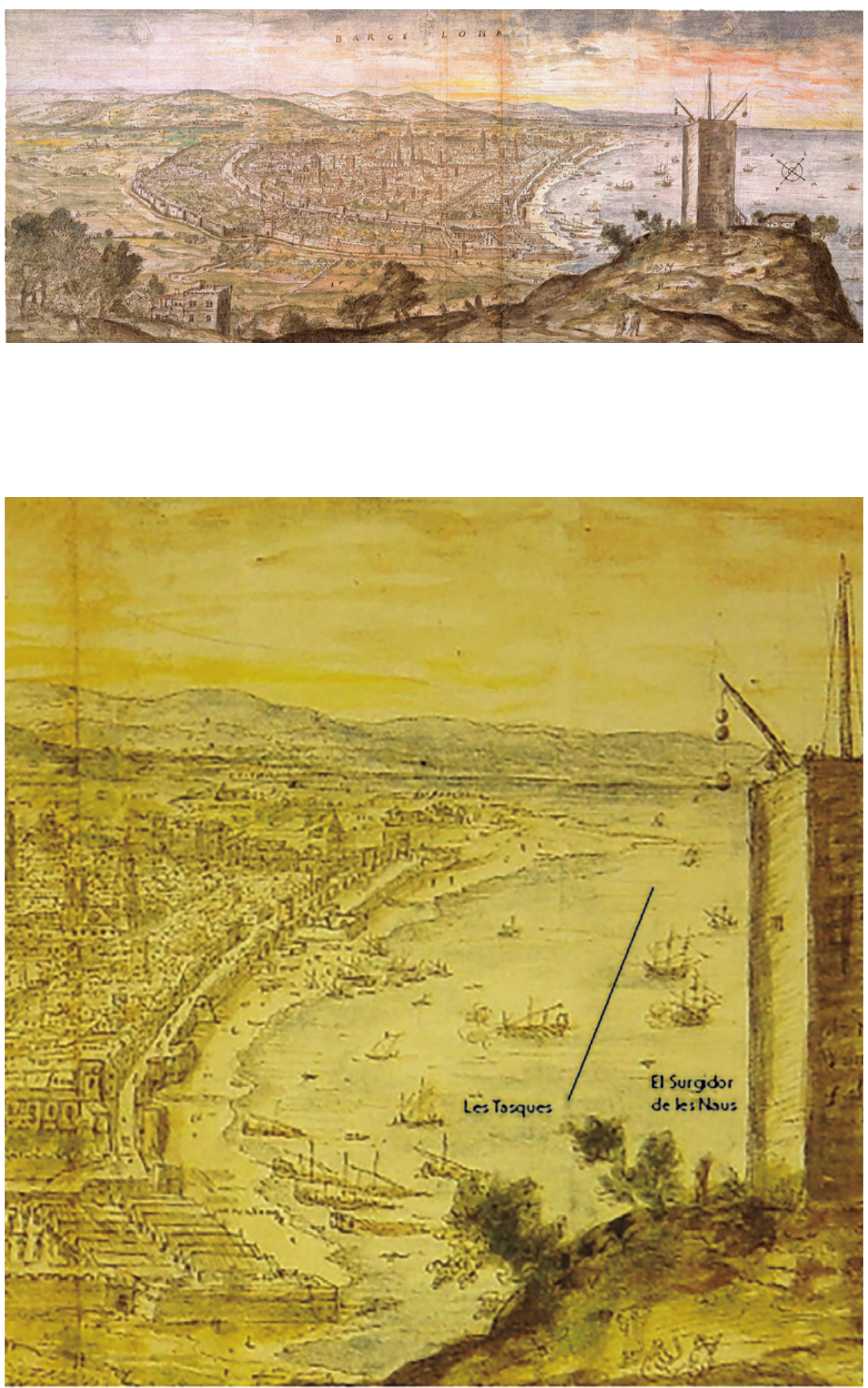

Figura 5. Tasques, Surgidor de les Naus. Basat en Wijngaerde, 1563 (MPH) 
temps o s'havien de reparar - igual que les galeres-, un espai que també era utilitzat per a la construcció de qualsevol tipus d'embarcació... Però era un port extraordinàriament desprotegit, a mercè de qualsevol temporal de vent $\mathrm{i}$ mar, encarat de ple als temporals de llevant: un perill evident, que es copsa a primer cop d'ull. Però existia un altre perill, aquest invisible: les Tasques.

La Tasca, o les Tasques, és el nom de la llarga barra de sorra que s'estenia parallelament a la costa, a uns 150-170 m, creant una mena de barrera submarina, que aflorava en part a la banda nord. De fet, era un perill i una protecció alhora. Representava un perill per a les embarcacions de més calat, que hi podien encallar, i protecció per a la ciutat i el seu port en l'evitar així que les naus enemigues s'acostessin. ${ }^{10}$

La perillositat per a les naus feu que aquestes ancoressin a l'altra banda de les Tasques, al lloc conegut com el Surgidor de les Naus, on hi havia 30 passes de fons (fig. 5). A l'espai entre les Tasques i la costa hi fondejaven les embarcacions petites i mitjanes. La barra sorrenca no era fixa, ni tenia sempre la mateixa posició i fondària. A més, disposava d'alguns passos que eren coneguts pels barquers i que permetien la navegació d'embarcacions de més calat, com les naus i les coques, per poder arribar a l'intraport o "platja de la ciutat». El pas més utilitzat es trobava a la banda de Framenors, on la fondària arribava als set pams, és a dir, uns dos metres (Pujol 2008, 162; Soberón 2014, 127). El risc de quedar atrapades en aquest punt no feia gaire recomanable per a les barques passar-hi, no pel fet de quedar encallades a la Tasca o a l'intraport, sinó que, en cas que s'aixequés un temporal i no poguessin sortir, corrien el perill de ser llençades pel vent i la mar contra la costa.

Aquesta situació diferent entre les naus i les barques que arribaven al port de Barcelona ja es contempla a les Ordinances de la Ribera de l'any 1258. Aquest text explica que les naus es troben ancorades, que les seves mercaderies es carreguen i descarreguen gràcies als barquers, que els mariners no poden baixar de la nau sense permís i que no es pot deixar la nau ancorada sense mariners. Només el guardià de la nau pot decidir llevar àncores i engolfar-se si hi ha temporal i el patró no hi és. En canvi, els llenys i les barques es poden treure a la platja (Capmany 1961, I, 68).

Probablement els fets que tingueren lloc el mes de juny de l'any 1359 ho expliquen prou bé. En el conflicte conegut com la Guerra dels Dos Peres, Pere el Cruel de Castella envià un estol format per 40 naus, 30 galeres i una quantitat indeterminada de llenys armats (segons Pere el Cerimoniós, cap. 22; segons la Crònica del Racional eren 32 galeres, 6 llenys, 21 naus i algunes barques), que arribà a Barcelona el 9 de juny. Lalmirall castellà «feu sorgir tot son estol en la dita platja de la dita ciutat» (Pere III, cap. 22), lloc on es trobaven deu galeres catalanes, a més de diverses naus. «Una fort gran encuirada, e els homes nostres destres en la mar meteren la dita nau

10 El juliol del 1454, cinc naus genoveses que perseguien dues navetes biscaïnes giren la proa quan les basques «es meteren pres les Tasques» (Schwartz, Carreras 1893, II, 184; Soberón 2014, 126). Un altre exemple es documenta l'any 1466, quan una nau genovesa fou presa a Tortosa i duta a Barcelona, buidada totalment, per tal que calés menys i així pogués passar un pas de la Tasca i ancorar just al davant de la ciutat. Quan arribà l'estol genovès per tal de recuperar-la no va poder passar la Tasca, i va haver de renunciar a recuperar la nau i donar-la per perduda (Capmany 1961, I, 69, nota 5; Fossati 2007). 
dins les Tasques, prop lo monestir dels frares menors», mentre les galeres les anaven colllocant entre l'espai que anava del cantó d'en Ciges, al capdavall del carrer de Regomir, fins al convent de Framenors, al costat de la Drassana Nova. L'endemà, 10 de juny, l'estol castellà tornà a atacar, sense èxit, i es retiraren: «Tira's tot lo dit estol de Castella fora les Tasques. E allí reposaren tota la nit» (cap. 23). El dimarts 11 de juny les galeres catalanes s'ajustaren una mica més, a l'espai comprès entre el cantó antigament conegut com l'Ancorer fins al cantó de Framenors. S'inicià un nou combat en el qual la utilització, per primera vegada, de bombardes en una batalla naval decantà l'èxit de la banda catalana, al causar greus desperfectes en la nau més gran de l'estol castellà. En conseqüència, «l'almirall de Castella, veent que ells estaven aquí més per llur dan e deshonor que per profit algun, manà tirar tot l'estol fora de les Tasques. E, en aquell lloc on lo navili ha acostumat de sorgir [el Surgidor de les Naus], collaren totes les naus per fer vela» i marxaren en direcció sud, rumb a Tortosa (cap. 24).

La protecció de la Tasca es podia convertir en una trampa. Per aquest motiu les naus i coques ancoraven a la banda de fora." Quan s'aixecava un temporal, les embarcacions petites, mitjanes i les galeres es treien en terra, mentre que les naus i coques havien de resistir al Surgidor de les Naus o bé llevar àncores i salvar el temporal a alta mar encarant la roda de proa a les onades, o bé fugir i buscar refugi a altres ports, com Sant Feliu de Guíxols al nord (Pujol 2018a) o Tarragona i Salou al sud (Carrère 1977). Els Dietaris, tant de la Generalitat com del Consell de Cent (Sans 1994; Schwartz, Carreras 1892), ens parlen de naufragis de naus a causa de temporals. El temporal pot arribar a fer llaurar les àncores o a trencar les gúmenes, i provocar que finalment la nau sigui llençada contra la Tasca, la riba o bé enfonsada.

Fent un repàs a notícies de finals del segle xiv i primera meitat del segle xv, trobem que el mes de gener de l'any 1395 una tempesta —o fortuna de mar i vent - que va durar vuit dies va provocar el naufragi d'una nau a Montjuïc; el mes de febrer de 1404 una tempesta provoca el naufragi d'almenys cinc naus: tres de catalanes - la d'en Guillem Saragossa, de dues cobertes; la d'en Carbó, d'una coberta, i la de l'Estornell, també d'una coberta- i dues de castellanes, i la mort de 30 persones (Pujol 1921, 160); el 2 de març de 1420 «periren en la plaja de la mar de Barchinona, per fortuna de mar, VI naus, ço és, la d'en Pujalt, la dels Barquers, la nau dels Viscahins, la nau d'en Olomar, la un d'en Bertran e la d'en Font»; ${ }^{12}$ sis anys després, el 7 de novembre de 1426, un nou temporal enfonsa dues naus, la d'en Janer i una nau castellana; el 14 de setembre de 1459 una gran tempesta de llamps i trons, que provoca destrosses en teulades i campanars de la ciutat, «ferí una nau castellana qui stava surta en la plaja, e mès-la a fons, que lo sendemà no’n aparech sobre l'ayga sinó la gàbia. (...) E ferí un hom qui dormia dins una barcha, vers les parts de Montgat, e matà'l» (Sans 1992, 151). Igual que a València. Aquí, el 24 d'abril de 1468 «arribaren en la plaja de Barchinona les dues naus armades per lo honorable en Ffrancí Anthoni

11 «Ormeiats fora la tascha o la ànchora en obert i ormeyades dins la tascha e la barba de la tascha» (Tintó 1992).

12 Sans 1992, 27. Ens informa amb més precisió del temporal que va tenir lloc. Les naus eren la d'en Pujalt, la d'Antoni Bertran, la d'Oldomar, de Sant Feliu de Guíxols, la dels Barquers i una nau castellana (Schwartz, Carreras 1892, I). 
Setantí, sens arbres, com aquells haguessen tallats per validíssima fortuna en la plaja de València, on se eren calades, e havien stat surtes per... jorns, per la qual stada lur se perderen en la dita plaja, entre naus e caraveles, VIII fustes, ultra una nau de CCCC botes e hun lahut gros de tràfech que havie presos, e portà ab bon salvament en la dita plaja de Barchinona» (Sans 1994).

Per a les embarcacions petites i mitjanes que no volien acostar-se en terra hi havia a vegades la possibilitat de fer-ho en "ponts de fusta», sempre que no haguessin estat desfets per un temporal. En coneixem alguns, construïts per desembarcar personatges notables, però que posteriorment sutilitzaren amb finalitat comercial. Bàsicament es tractava dels que havien estat construïts al davant de l'àrea mercantil, segons consta també als Dietaris esmentats.

La perillositat del port de Barcelona per a les naus no era l'únic inconvenient. S'hi sumava la necessitat d'ancorar a molta distància de la costa —a més de $170 \mathrm{~m}$-, fet que requeria barquers per a les tasques de càrrega i descàrrega i, per tant, un temps i una despesa que augmentaven si feia una mica de mala mar i no es podien acostar les barques a la nau, pel perill de collisió o que caigués una caixa i piqués contra els barquers. Una mica de mala mar no era un perill per a les naus, però impossibilitava la feina de càrrega i descàrrega a les barques. Era un perill tant per a aquestes com per a la mercaderia i els barquers. Segurament les assegurances no cobrien els dies de més, o deurien ser més cares. Així, la tendència fou que les naus, coques i naus grosses d'altres potències marítimes, com Gènova, deixessin de fer escala a Barcelona i optessin per un altre port més segur, com el de Ciutat de Mallorca, on no solament hi havia dos ports excellents, el de la Ciutat i el de Portopí, sinó que hi podien carregar i descarregar directament en un moll. No només era una qüestió de temps i diners, sinó també de seguretat i facilitat de càrrega i descàrrega.

Al segle xv pràcticament tots els grans ports de la Mediterrània Occidental ja tenien un moll d'obra (Marsella, Gènova, Nàpols, Messina, Ciutat de Mallorca, etc.) i els que no en tenien eren, gairebé tots, ports naturals excellents (Cartagena, Bríndisi, Constantinoble, Ciutadella, Maó, etc.). La seva primera funció no consistia només en la protecció contra el mar i l'enemic — atès que en molts casos tenien una bona protecció natural— sinó la facilitat de càrrega i descàrrega que oferien a les naus mercants. L'excepció eren Barcelona i València, que presentaven una costa sorrenca totalment exposada als temporals i a l'enemic.

L'any 1439 és la quarta fita cronològica. El 1434 els cònsols de la Llotja i un grup de mercaders de la ciutat plantegen que «en la plaja de la mar vers les Tasques se poria fer $\cdot \mathrm{I} \cdot$ moll, per lo qual se seguire gran profit e bé a la dita Ciutat e a la mercaderia e al ben publich» (Soberón 2014, 129). E1 1438, Alfons el Magnànim concedeix el privilegi de cobrar el dret d'ancoratge a la ciutat per fer moll. L'any 1439 la ciutat decideix construir el primer moll al davant de l'Esperó de Santa Clara i del monestir de Santa Clara (Schwartz, Carreras 1892), per la qual cosa es coneixerà com el Moll de Santa Clara. ${ }^{13}$ La tècnica

13 Soberón $(2012,59)$ posa en dubte que el moll de Santa Clara de la vista de Wijngaerde sigui el de 1439. Creu que el moll es va fer directament sobre la Tasca, i que aquest conjunt de pedres podria correspondre a un espigó fet el 1485 per evitar-ne l'erosió. El veritable moll del 1439 es trobaria sota el Parc de la Ciutadella. 
triada va ser la construcció de grans caixes de fusta que es remolcaven fins al lloc desitjat, s'omplien de pedra i morter, i s'enfonsaven; però la primera caixa enfonsada es va desfer al cap de poc, amb el primer temporal. ${ }^{14}$ La problemàtica tècnica obligà que en els anys 1440-1441 s'anessin a buscar mestres especialitzats en la construcció de molls a Siracusa, Candia i Rodes, com el mestre Antoni Genovès (Pujol 2008, 162; Soberón 2014, 137). Una proposta que finalment es desestimà fou utilitzar la vella nau Juliola, carregar-la de pedra i enfonsarla. A partir de 1455 el sistema de caixes fou canviat pel llançament de grans blocs de pedra duts fins al lloc gràcies a tres pontons - un tipus d'embarcació molt ampla, d'uns $6 \mathrm{~m}$ al mig i al dragant de popa, sense coberta i amb una estructura molt reforçada-, que disposaven de dos pals (el bauprès i l'arbre maixellàs) i un argue que servien sobretot per a la manipulació dels blocs de pedra, una mena de càbria. A més, disposaven també de rodes de carregar que ajudaven a manipular pesos. Els pontons eren remolcats per dues barques de 9 m de llargada, o bé anaven a vela si el vent era favorable (Soberón 2014, 133). Les obres, amb intermitències, es realitzaren des del 1439 fins al 1456, moment en què s'abandonaren a causa de la manca de pressupost i de la desfeta dels treballs ja realitzats, per culpa dels temporals.

Acabada la Guerra Civil (1462-1472) s'inicia el segon projecte, situat més al sud, conegut com el moll de Santa Creu (fig. 6), sota la direcció del mestre Stací d'Alexandria, amb el qual ja s'havia contactat l'any 1457 per la seva experiència en obres portuàries a Candia, Palerm i Gènova. La segona obra es realitzà entre els anys 1477 i 1487, i s'arribaren a construir uns $100 \mathrm{~m}$ de llargada amb una amplada de $15 \mathrm{~m}$, però, com en el primer intent, el projecte acabà en fracàs. Havia de ser, segons el mestre que van fer venir, Stací d'Alexandria, l'any 1479, un moll que creés un bon port de refugi: «ell stara segura la maior nau del mon, e ab maior tempestat del mon entrara stara dintre lo dit port e moll securissima de la tempestat de la mar e de perill de tots enemics» (Soberón 2012, 63, nota 25). Stací va tenir discrepàncies amb el Consell de la Ciutat, ja que ell volia començar a girar cap al sud el braç del moll, mentre que el Consell demanava fer-lo encara més llarg dins del mar (Cabestany, Sobrequés 1972, doc. 39). En la construcció d'un moll no solament era essencial el capital, sinó el saber tècnic, la voluntat de fer, és a dir, el voler i el poder, tenint en compte que sempre hi podia haver opositors, com els membres del Consell de Cent, que no ho trobaven necessari, o bé el Gremi de Barquers i de Gondolers, que devia estar-hi lògicament en contra (Soberón 2012, 2014).

Aquesta quarta fita cronològica no és important per a la construcció del moll, que veiem que va acabar sense èxit, sinó pels canvis que provocà en la dinàmica dels corrents del litoral. A partir d'aquesta data la barrera artificial dels dos molls afavorí l'acumulació dels sediments marins i fluvials a la seva banda nord, mentre que pel sud causà l'efecte contrari, provocant l'erosió de tot el litoral situat entre els dos molls i Montjuï.

14 En la primera caixa de fusta es va celebrar una missa de benedicció al seu interior, muntant-se un petit altar, les primeres pedres del qual es van marcar amb l'escut de Barcelona (Pujol 2008, 162). 


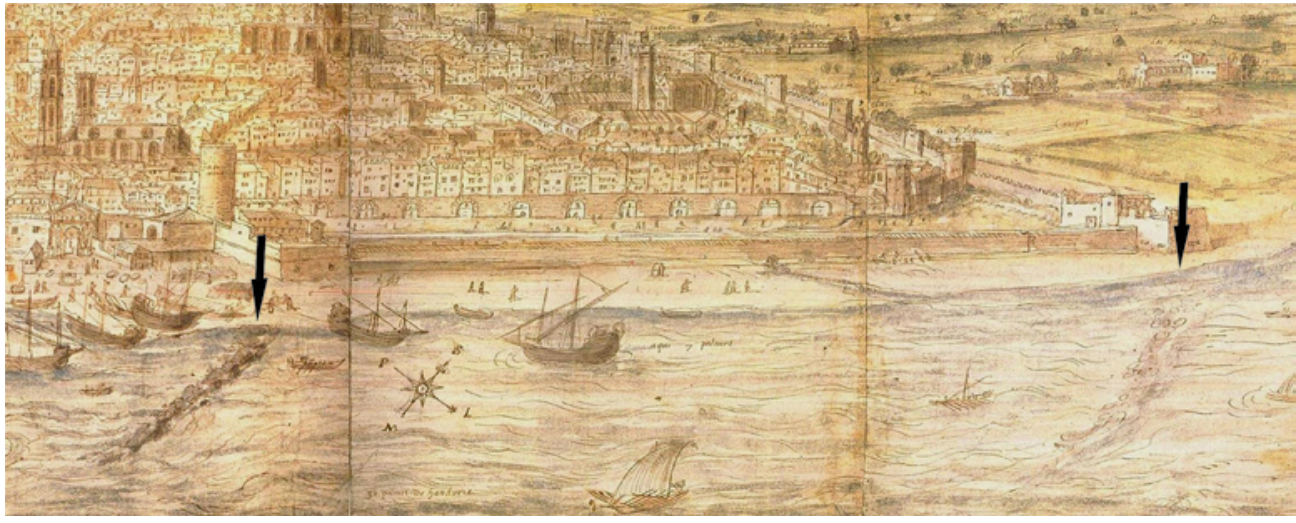

Les llevantades afectaven sobretot l'àrea sud de la ciutat, on la platja cada cop era més estreta. Els edificis construïts a la vora del mar, com ho era la Drassana Nova, serien els més afectats, evidentment, com ja succeïa anteriorment, per la seva situació en un indret de risc (Mutgé 2004). El 1449, un dels pontons que s'utilitzaven per a la construcció del moll va ser arrossegat pel vent cap al sud, fins a topar contra l'esperó de la Drassana (Soberón 2014, 134). E1 1457 i 1462 es documenten els primers danys a la platja de la Llotja; el 1464 — «el mur nou lo qual bat la mar»- i 1466 — «fer en lo loch hon los fonaments del mur per fortuna de mar l'any present son enderrocats»- s'han de posar pedres i una filada de $21 \mathrm{~m}$ d'estaques de vern (de 4,5 m de $11 \mathrm{arg}$, dels quals $2,5 \mathrm{~m}$ eren dins de l'aigua) al peu de la muralla de mar del costat de Framenors, i una palissada a la plaça del Vi per evitar l'erosió de la platja; el 1516, un temporal destruí dues illes de cases que donaven al carrer de les Polleres (Soberón 2012; Fossati 2007; Cabestany-Sobrequés 1972; Capmany 1961). A la vista de Barcelona realitzada per Vermeyen l'any 1535 (fig. 7) es veu clarament aquest doble efecte de regressió i transgressió del litoral, l'acumulació de sediments a la banda nord de la ciutat i l'erosió de la platja al costat sud, amb una drassana gairebé dins del mar i un tram de la muralla i l'esperó de la drassana dins del mar, totalment sotmès als embats de les llevantades. Una de les conseqüències de la regressió litoral fou la minva de gent de mar que vivia al sector sud, que es desplaçà cap al barri de la Ribera, fet que el va consolidar com a barri mariner per excelllència de la ciutat.

\section{SANT FELIU DE GUÍXOLS}

Per entendre l'origen del port de Sant Feliu de Guíxols cal recordar que bona part de la costa dels comtes d'Empúries, Girona i Barcelona fou cedida als ordes benedictins que s'encarregaren d'administrar aquestes territoris, impulsant el seu repoblament i la seva explotació econòmica, tal com trobem de nord a sud: els
Figura 6. Detall primer i segon moll. Wijngaerde, 1563. 
Figura 7. Vista Vermeyer (1535), Barcelona des de Montjuïc. Publicat al Civitates Orbis Terrarum (1572).
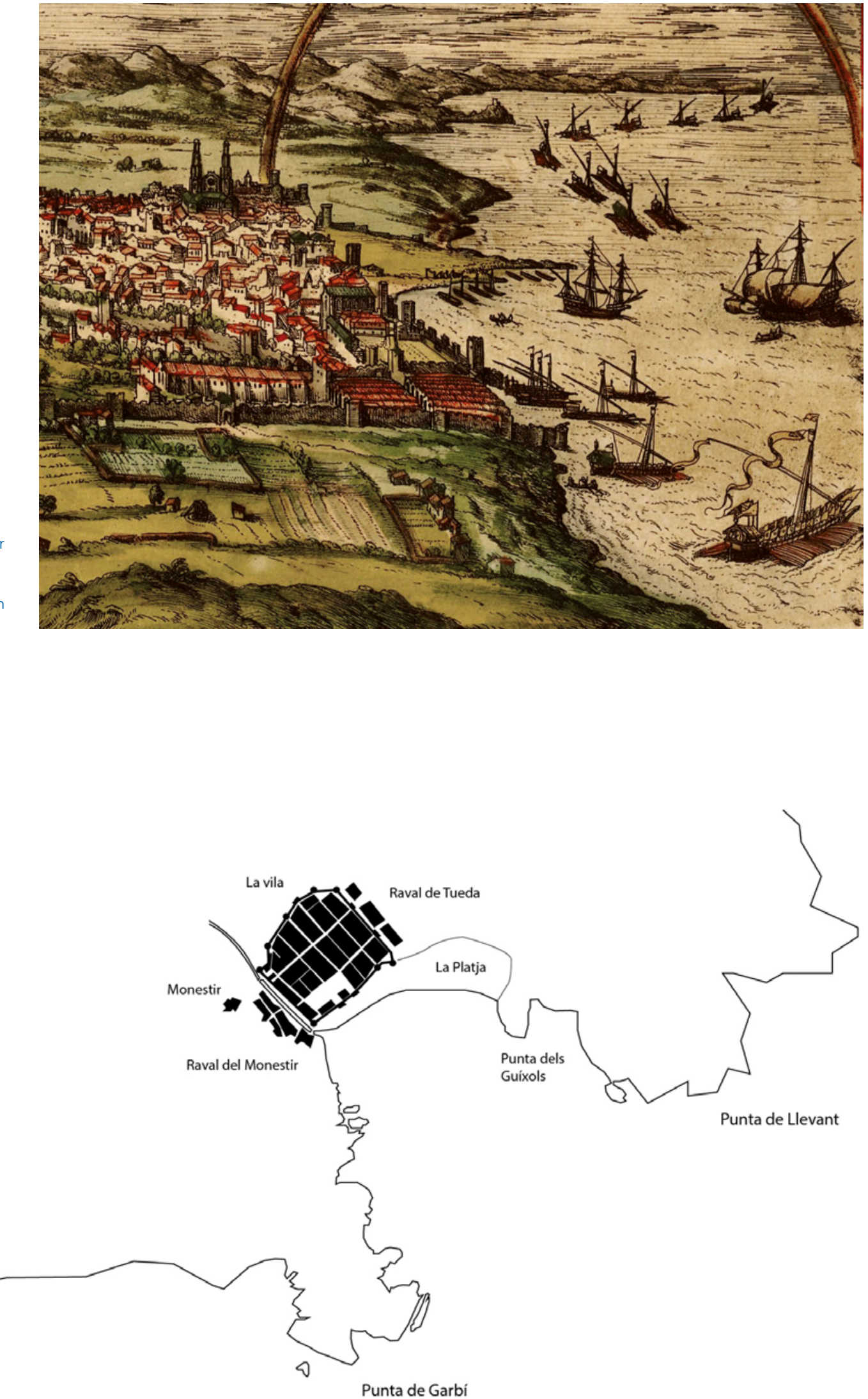
monestirs de Sant Quirze de Colera, Sant Pere de Roda, Santa Maria de Roses, Sant Feliu de Guíxols i Sant Pol de Mar. En alguns hi trobem la presència comtal pel fet de coincidir-hi la ubicació del port comtal, on tindrà lloc la principal connexió marítima — per tant, el port comercial— i també on el comte instal-larà la seva drassana.

En el comtat de Girona, el port comtal fou des d'un bon principi Sant Feliu de Guíxols, i no la via natural cap al mar seguint el riu Ter cap a Torroella de Montgrí. La ruta que unirà Girona al mar serà el camí que passava per Llagostera fins a Sant Feliu de Guíxols, amb un total de $34 \mathrm{~km}$. Aquesta via fou arreglada i reformada per un mestre d'obra francès l'any 1322, el qual la devia eixamplar, pavimentar, anivellar, eliminar-ne grans pendents i construir-hi ponts, facilitant així la connexió per terra en convertir-la en un bon camí de carro.

El port de Sant Feliu de Guíxols, des d'un punt de vista geomorfològic, tenia - i té- unes característiques excel-lents. Disposa d'una cala fonda i delimitada per la punta de Llevant, que la protegeix dels temporals de tramuntana i llevant, i la punta de Garbí, al sud. A més, al seu interior es troba la punta dels Guíxols, que afegeix més protecció a l'espai situat més al fons de la cala. Per altra banda, la seva fondària, $10-12 \mathrm{~m}$, en permetia l'ús als grans vaixells mercants com a lloc d'ancoratge, i a poca distància de la riba. A més, hi ha dos cursos fluvials que hi desemboquen: la riera de Sant Feliu i la de Tueda (fig. 8). És un punt de refugi perfecte, que es podia aprofitar també com a port d'escala. Com a port de Girona, esdevé un equipament comercial i militar.

L'evidència documental de les seves qualitats, que en fan el millor port de refugi de la Costa de Llevant, la trobem en el fet que hi hivernà l'estol català-occità $\mathrm{i}$ pisà que conquerí Mallorca l'any 1114. Tot que l'estol pisà arribà inicialment a Blanes - el primer port català on tocà- no es dirigí cap a Barcelona sinó cap a Sant Feliu de Guíxols, un port més segur.

La vila, que s'havia creat sota la protecció del monestir, al marge dret de la riera, experimentà un augment de població al segle XıIı i es creà una nova àrea urbana, a l'altra banda de la riera, al seu marge esquerre. Creiem que l'existència de la drassana comtal, prèvia a l'expansió urbana, condicionà aquesta, especialment la plaça. ${ }^{15}$ En tota la documentació conservada de la segona meitat dels segles XıIı i XIV sempre apareix la plaça a l'interior, i la drassana al costat de mar. Coincideixen en el mateix punt, i sovint la documentació fa servir els dos termes alhora — plaça i drassana- d'una forma ambigua $(1347,1352)$. Només a partir del moment en què es construirà el tram de mar de la muralla, l'any 1356, aquesta dividirà la plaça de la drassana, partint aquest espai més o menys conjunt en dos.

No sembla que la drassana fos una gran construcció, sinó un espai més o menys delimitat, potser amb un muret o unes estaques que indicaven la seva superfície. A mitjan segle XIII la drassana pertanyia al monestir, un fet que devia ser bastant recent. Segurament fou cedida per Jaume I en l'època de l'expedició a Mallorca, en què només 12 galeres escortaren el comboi de conquesta de l'illa, una de les

15 La nova àrea urbana creix al voltant de la drassana, tal com es documenta l'any 1258: «de ex termino cantono domorum Berengariu Peleti usque ad rieriam quod labitur per villa predictam». 
quals hauria estat construïda a la drassana de Sant Feliu. ${ }^{16}$ En el moment en què el rei concentrà la construcció de galeres a Barcelona, l'abat de Sant Feliu acabà cedint l'espai de la drassana a la universitat de la vila, que farà com Barcelona: transformar l'ús de l'espai de militar a comercial.

A Sant Feliu també podem observar les tres àrees funcionals, a partir de mitjan segle xıIr: l'àrea militar, que teòricament es trobava al davant de la plaça de la Vila, atès que no sembla que ho fos a la pràctica; la comercial, que es trobava al davant de la vila; i la pesquera, que s'havia anat desplaçant cap a llevant, cap a Tueda.

Que Sant Feliu de Guíxols era un port de refugi és evident. N'és bona prova que, el 22 de març de 1464, la nau de Francesc Salelles rebé ordre d'anar cap a Sant Feliu en comptes de Barcelona quan tornava de Menorca, «per seguretat». Un cop a Sant Feliu va caure una gropada com mai s'havia vist. Caigué tanta aigua que la nau es va obrir tota i es va desfer sobre el mar. I no va ser l'única: una altra nau que hi estava ancorada, propietat de Bernat Oliver, s'emplenà de tanta aigua de pluja que també es va enfonsar. Per a Salelles fou un fet veritablement excepcional. No era el temporal de mar i vent, ni la falta de moll o de protecció natural el que feu enfonsar les naus, sinó la quantitat d'aigua que va caure del cel: «e diuen los qui han memorie de LXX anys que may veren ni ohiren dir que a Sent Feliu se perdés fusta, e sera tant fort temps que may tal no ych fou» (Pujol 2018a).

Un altre aspecte que comenta Salelles és que hi havia dues naus carenant - la d'en Melcior i la d'en Nicolau Pla - però no explica si resultaren afectades per l'aiguat. La construcció naval de grans vaixells mercants, com coques i naus, es duia a terme en moltes més poblacions que no pas on aquestes es carenaven. És a dir, hi havia força ports on es construïen naus, però menys on es reparaven o carenaven.

Les naus, com totes les embarcacions, es construien a la platja - i les galeres, també a les drassanes-, mentre que, quan s'havien de calafatejar o reparar, totes les embarcacions es treien en terra, tant les barques de pesca com les de cabotatge, els llenys i fins i tot les galeres, excepte les naus, coques i naus grosses, que pel seu volum i pes no ho permetien. En aquest cas només es podia carenar una nau buidant-la de tot el que portava: càrrega, llast, massarés, etc. Alleugerida i calant menys, era portada cap a la riba, posant-la de costat. Llavors es passaven caps $i$ antenes que lligaven la nau a argues situats a la platja que anaven tensant els caps i inclinant la nau en direcció a terra (fig. 9). Lentament la nau anava exposant a la banda de mar l'obra viva fins a deixar a l'aire la quilla (d'aquesta maniobra se'n deia «donar lats» $\mathrm{i}$ «mostrar carena»). Llavors, per la banda de mar, s'acostaven amb una barca, pontó o rai els mestres d'aixa i els calafats per reparar el buc o calafatejar. 
Nau mostrant carena
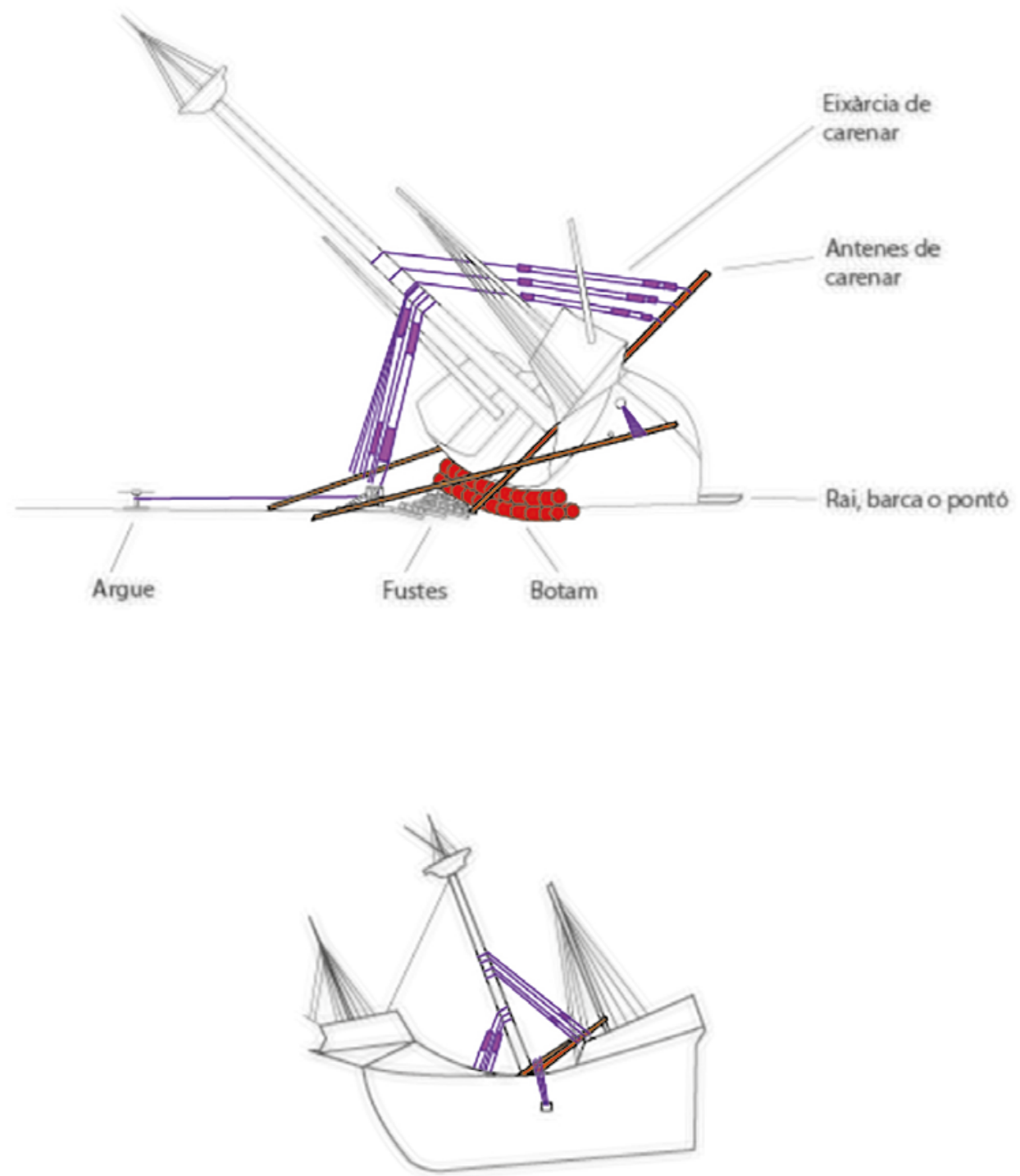

Figura 9. Carena de nau $(\mathrm{MPH})$ 
És bastant clar i lògic que una nau carenant no podia estar en una platja com la de Barcelona, totalment exposada a la mar. En el cas que s'aixequés un temporal, la seva pèrdua seria inevitable. No hi havia temps de desfer els caps, allunyar-la de la riba, posar-hi llast, muntar tota l'eixàrcia, les veles, les àncores, dotar-la de tripulació i fer-se a la mar. Per aquest motiu a Barcelona es podien construir naus però no es podien carenar. A Catalunya només hi havia tres ports on es carenaven naus al segle xv: Palamós, Sant Feliu de Guíxols i Tortosa —en aquest cas un port fluvial- ${ }^{17}$ mentre que als regnes de València i Mallorca només es portaven a carenar a Portopí i a Eivissa.

Així, Sant Feliu de Guíxols esdevé el principal port carenador i alhora constructor de naus, on es construïen gairebé tantes naus com a Barcelona. La raó no es troba en el pes polític i econòmic de Sant Feliu de Guíxols, ni de Girona, sinó en el fet que, a Sant Feliu, gent de la vila, de Girona i també de Barcelona hi invertia en la construcció de naus. A vegades trobem barcelonins que construeixen naus a Sant Feliu en comptes de fer-ho a Barcelona, per la seguretat del seu port, pel saber tècnic d'alguns dels seus mestres d'aixa (especialitzats en la construcció de naus) i probablement per altres aspectes, com la matèria primera i el preu. Sant Feliu de Guíxols no només es convertí en el port de Girona, sinó en port complementari al de Barcelona, com a port de refugi, port de construcció de naus i port carenador de naus, aspectes que la capital no podia complir o complia en part.

Tot i ser un port de refugi natural excellent, coneixem dos projectes de construcció d'un moll a Sant Feliu de Guíxols, que segurament tenien la intenció de facilitar la càrrega i descàrrega de mercaderies més que no pas la protecció de les naus del seu port. El primer projecte data del 15 de desembre de 1453, en què s'acorda la construcció del moll entre el rei, l'abat i la universitat. L'obra s'inicia el 12 de novembre de 1457 cobrant-se el dret de l'ancoratge destinat al seu finançament. En un moment que desconeixem — segurament abans del 1462 - l'obra s'aturà. El segon projecte té lloc a partir del 1493, quan Ferran el Catòlic ${ }^{18}$ atorga privilegi per a la construcció del moll. L'obra s'inicia el 1496, i funciona intermitentment fins a l'any 1512, en què, a causa de les dificultats pressupostàries, es demana que el llegat Sans, d'unes 200 lliures, es destini a la construcció del moll (fig. 10).

El Fortim a la punta dels Guíxols, conegut com a moll medieval, no és realment un moll, i segurament tampoc no és medieval. Es tracta més aviat d'una muralla que d'un moll, pel seu aspecte i la seva alçada. És molt probable que els dos projectes de construcció del moll, de mitjan i de final de segle, tinguessin aquesta punta com a punt de partida. Però no hi ha cap indici conegut de l'existència del moll medieval. El tercer projecte (Vivo 2005) data de finals del segle Xvi, i tot sembla indicar que seria aquest l'origen del moll actual, i molt probablement del Fortim.

17 El 1431, quatre naus preses a Marsella són reparades a Sant Feliu de Guíxols i a Palamós (Pujol 2018a; Costa 1988).

18 «al redreç del exercici maritim lo qual se diu se pora fer finalment si en la mar de la dita vila era construhit un port e que vista la opportunitat que la mar de dita vila te ab les puntes de les penyes qui entren dins aquella retent gran principi de port prest e ab no molta despesa dit port se pora fer, (...) la utilitat que del dit port prove no sols als poblats en dita vila mes encara a tots los nevegants per lo reffugi e reparo que llus fustes e navilis poran haver en aquells e per consaguent esser la dita fabrica de dit port gran beneffici a la cosa publica» (Pujol 2018a). 


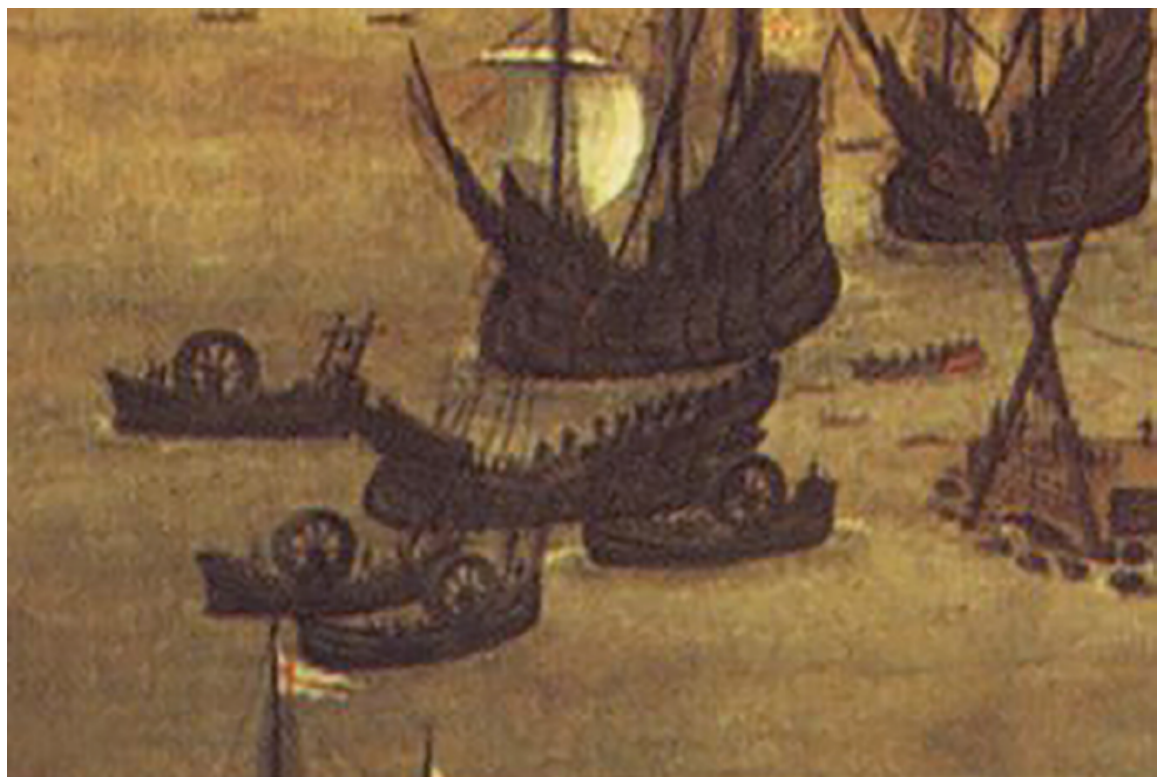

Figura 10. Pontó i roda. Detall del port de Gènova. Pintura anònima del 1481, obra inacabada. Cristoforo de Grassi, l'acabà el 1597. Es conserva al Galata Museo del Mare, Genoa.

En les demandes per a la construcció del moll es diu sobretot que servirà per redreçar el comerç marítim. No es tracta d'una iniciativa aïllada: hem vist que, a Barcelona, els dos projectes de construcció de moll coincideixen temporalment amb els dos projectes de Sant Feliu, però també en altres ports de la Corona d'Aragó i de la Mediterrània que no disposaven de moll de pedra, com Tarragona, València i Màlaga. ${ }^{19}$ Tot sembla indicar que la necessitat de donar protecció i sobretot facilitar la càrrega i descàrrega de les naus i naus grosses del segle xv obliga les ciutats portuàries a construir molls i evitar així perdre posicions en el sistema portuari de la Mediterrània.

Una altra estructura associada al port fou la torre de Sant Elm, que estava situada dalt de la punta de Garbí, i probablement tenia la mateixa funció que les dues torres del monestir, que es coneixen com la torre del Fum i la torre del Corn. ${ }^{20}$

19 A Tarragona, el 1483, l'arquebisbe Pere d'Urrea rep privilegi reial per canviar el pont de fusta per un moll de pedra, del qual s'encarregaren els mestres Pedro i Juan Burgueta de Navarra, que entre el 1491 i el 1510 arribaren a construir un moll de 100 canes de llarg (uns 160 m) (Pujol 2008a). A València, el port es trobava a 4 km de la ciutat, a Vilanova del Mar. El 1483 el rei dona privilegi a Antoni Joan de construir i gestionar un pont de fusta, mentre que el 1491 el mateix rei Ferran el Catòlic dona privilegi per construir un moll de pedra, el qua es feu sota la direcció del mestre venecià Joan Cabot Montecalunya, però que fou aturat el 1494 per l'oposició del consell de València, i sobretot d'Antoni Joan, per la competència a què es veia sotmès (Hinojosa 1989, 159165; Hinojosa 1996, 271-272). València era un port totalment exposat als temporals, com el de Barcelona. «Non ha porto alcuno, ma sola spiaggia» - així el descriu un mercader milanès el 1515- «et anche quelle non si accostano alla terra, ma stano in mare meza lega o circa, et scaricano con le barchette» (Igual 2014, 102).

20 El port de Palamós es creà com a port alternatiu al de Sant Feliu de Guíxols. El 1277 Jaume I encarrega al seu batlle Astruc Ravaya la compra del castell de Sant Esteve i el seu terme, amb vista a la creació d'un port reial. E port de Palamós augmentà la seva importància a partir del 1330 a causa del conflicte que enfronta l'abat de Sant Feliu i els jurats de la vila pel mesuratge. El 1334, un conflicte entre els ports de Sant Feliu i el de Palamós fou resolt pel rei a favor de Palamós. Durant el segle xv Palamós seguirà essent un port de refugi i port carenador, tot i alguns problemes a causa de les terres i grava que provenien de la riera de Palafrugell i obstruien l'espai portuari el 1407. L'única referència a l'existència d'un moll data del 1517, quan al port de Barcelona hi ha treballant Antoni Sastre, «magistrum portus sive molli ville de Palamosio» (Madurell 1970, 86, doc. 1). 
La funció del port de Sant Feliu de Guíxols en el sistema portuari català sembla múltiple. Tant és un port pesquer com militar — per la seva funció comtal一, però també fa el seu paper en les xarxes marítimes com a port de refugi i escala, port comercial de segon ordre per la seva vinculació amb Girona i port complementari al de Barcelona, per la construcció, carena i refugi de naus (moltes de les quals amb destinació a Barcelona o provinents d'allà). A més, té importància fiscal, tenint en compte que des de 1127 s'havia habilitat juntament amb Barcelona com a únic port on es podia pagar la taxa de pas dels vaixells genovesos a la costa entre Niça i Salou, a banda de les altres imposicions aplicables a qualsevol port carregador i descarregador de la costa catalana.

\section{ROSES}

A primer cop d'ull, el que destaca a Roses és la seva situació i les condicions nàutiques o geomorfològiques del lloc on es troba. Situat al fons del golf de Roses, l'indret, per si mateix, dona protecció als vaixells que volen passar el cap de Creus $^{21}$ en direcció nord, cap a Marsella o Gènova. El paper de port de refugi augmenta per la seva localització concreta, al costat nord, darrere de la punta del Morrell (o de la Poncella), a l'àrea on es forma la badia de Roses. De tot el golf de Roses, és el lloc on les embarcacions es troben més ben protegides dels temporals de vent i mar de llevant, i també dels temporals de nord (gregal, tramuntana i mestral), o almenys de la mar que aquests vents puguin aixecar (fig. 11). ${ }^{22}$

Les dimensions del golf de Roses, de la seva badia i de la seva llarga platja permeten tenir tantes embarcacions com es vulguin ancorades al seu interior, o bé tretes a la platja. Això és el que volia dir Ramon Muntaner quan va sentenciar que el port de Roses era «lo mellor port de Catalunya e el major, que tot lo navili que fet és hi poria estar» (Muntaner, cap. 122). En el capítol següent, quan parla de l'arribada de l'estol croat a Roses, sorprès per la gran quantitat de vaixells que hi havia, escriu: «E axí matex viu tot lo navili en lo golff de Roses, que era tota infinitat de veer» (Muntaner, cap. 123).

21 No hem volgut tractar el port de Cotlliure, amb una funció similar a l'altra banda del cap de Creus, però tampoc ignorar-lo, atesa la seva importància dins del sistema portuari català. Com a port del comtat del Rosselló, esdevingué a més el port continental del regne de Mallorca (1276-1343). En el segle XIII destacà l'activitat militar, segurament promoguda pel comte Nunyo Sanç (1190-1242), de qui sabem que les seves galeres van prendre un vaixell pisà prop de Barcelona, un altre a Marsella i un altre al davant del Tíber, que el 1210 es construien tarides a Cotlliure, i que participarà amb diverses galeres i altres embarcacions a la conquesta de Mallorca el 1228. Com tot port comtal, havia de tenir la seva drassana, encara documentada el 1345 i, com a infraestructura important lligada a la seva funció comercial, l'existència d'un moll de pedra (Palou 1992). A finals del segle XIII es destinaren 500 sous de la lleuda al port de Portvendres — que actuava de port complementari al de Cotlliure - i altres quantitats a la construcció d'infraestructures portuàries a Cotlliure per a ús dels mercaders (Orvietani, 2001, 78-80). Tot i les seves bones condicions nàutiques, el camí fins a Perpinyà era llarg, uns 30 km, i sovint es feia malbé (el mes de gener de 1344 les inundacions el van malmetre. ACA Cancelleria, Cartes Reials, Pere III, 2629). Per diferents motius es buscaren alternatives, com la platja de Canet (Salicrú 2003).

22 Aquest és un condicionant que podria haver afavorit el trasllat del port comtal d'Empúries i la seva capital. Empúries es troba totalment exposada al mar i vent de llevant, i també als vents de nord i a la mar, que es va aixecant a mesura que el vent avança seguint el golf de Roses de nord a sud. 


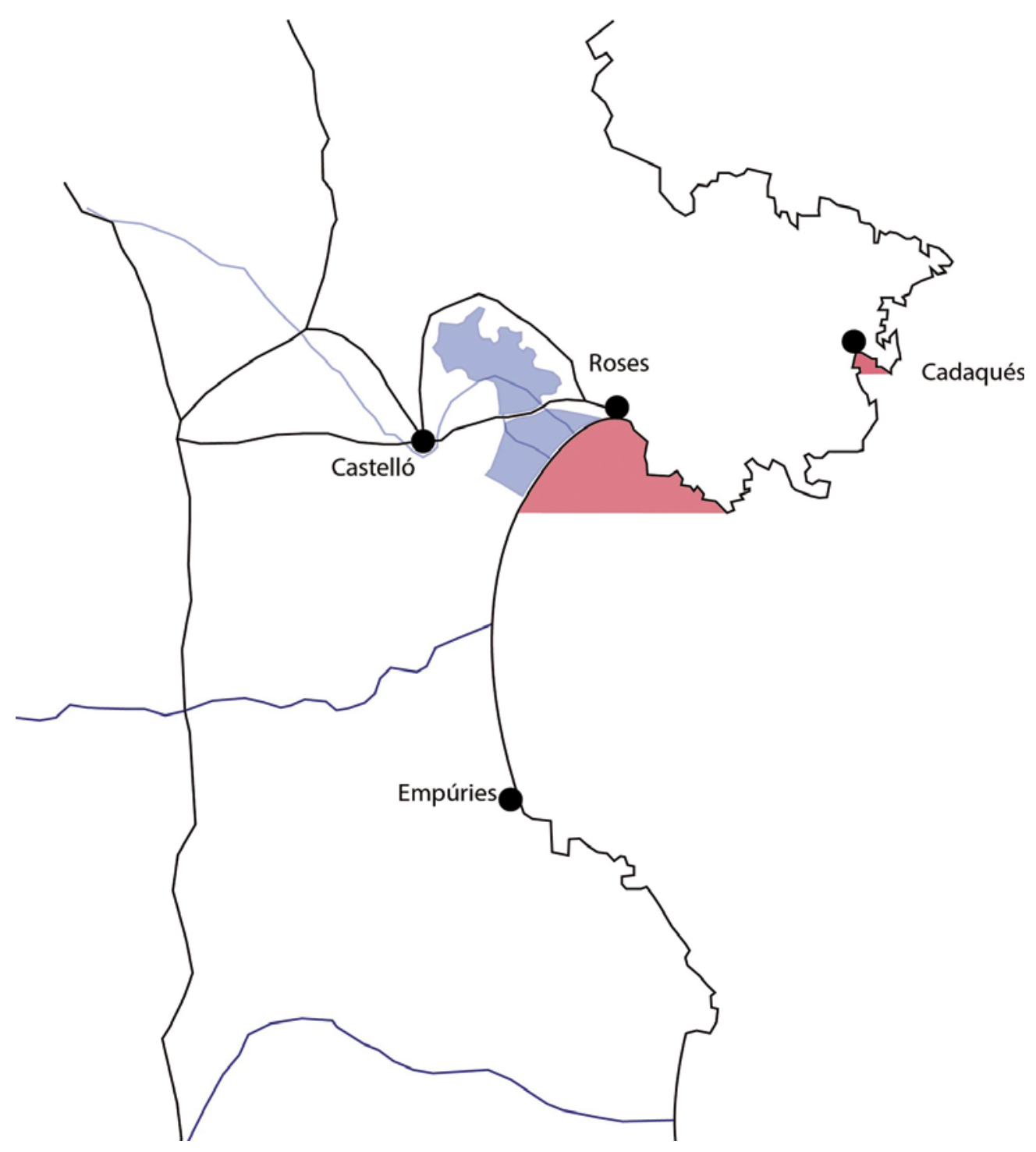

Figura 11. Golf de Roses: Castelló d'Empúries i Roses (MPH)

Segurament aquest és el motiu pel qual Roses fou triada en diverses ocasions com a lloc de concentració dels grans estols reials, els estols de conquesta, com el de l'any 1354 destinat a la Guerra de Sardenya. ${ }^{23}$ Els altres punts de la costa catalana que tingueren aquesta funció foren Salou el 1228 i diverses vegades - 1282, 1324 i 1393 - el de Portfangós, al costat sud del delta de l'Ebre (Gilabert 2008).

Roses adquirí la funció de port comercial i militar a partir del moment, o poc després, que la capital comtal es traslladés d'Empúries a Castelló, a mitjan segle XI. A Roses, situada a 9 km de Castelló, s'hi podia arribar pel camí que travessava l'estany de Castelló, en el punt que es dividia en l'estany superior i

23 Pere III, Crònica, cap. 35: «reculliren en lo port de Roses, del comtat de Empúries, hon se devien ajustar les galeres y navilis necessaris al nostre passatge». 
l'inferior, excepte quan anava molt ple d'aigua i es feia impracticable el camí. Llavors calia fer la volta a tot l'estany cap a Vilaüt, Pedret i Marzà i Vilanova. És molt probable que les embarcacions de poc calat, petites i mitjanes, poguessin entrar pel Grau i, navegant per l'estany, arribessin fins a Castelló. Recordem que Castelló, tot i ser el centre polític de la comarca, estava descentrada respecte a les principals vies, tant la marítima com la terrestre. En aquest cas encara calia recórrer $11 \mathrm{~km}$ per fer el camí fins arribar a la via Francisca. Castelló tenia una centralitat política i administrativa com a capital comtal, una centralitat econòmica reduïda al territori del comtat, però totalment descentrada respecte a les rutes més importants, $\mathrm{i}$ fins i tot cal recordar, per la seva importància a l'època, la seva nul-la centralitat religiosa, tot i la reivindicació del bisbat i la construcció de la catedral a Castelló d'Empúries.

Prèviament a la designació de Roses com a port comtal, la vila ja existia. El seu origen és similar al de Sant Feliu de Guíxols. L'origen urbà s'ha d'establir a partir de la fundació del monestir de Santa Maria de Roses, al segle x. Era un recinte fortificat dalt del puig de Santa Maria, que disposava d'una àrea amb població civil al voltant de la plaça del Monestir, i la resta estesa pels masos i vilars del terme. A partir del moment en què es convertí en el port comtal, la població va créixer, i en els segles XI i XII es creà una nova àrea urbana als peus del puig, al seu costat de ponent, entre el monestir i les dues rieres: és el barri del carrer de la Creu. El creixement urbanístic continuarà durant la segona meitat del segle XIII amb un nou eixample en el vessant sud, que conduïa cap al port, i quedava limitat pel costat oest per la riera i a l'est per la Coromina de l'Abat. El carrer Major enllaçava la plaça del monestir amb el barri del Port (fig. 13) (Pujol, 1997; Pujol 2018b).

En aquest moment, a finals del segle xiII, Roses va protagonitzar bona part de la Croada contra Catalunya en convertir-se en el port logístic de les tropes franceses i croades al sud del cap de Creus, l'any 1285. Adquirí aquesta nova funció de port base - que continuarà en els diversos conflictes de l'era moderna- on es concentrava tot allò necessari (armes, munició, queviures, magatzems, reparació naval) perquè l'exèrcit invasor pogués avançar cap al sud, cap a Barcelona, tant per terra —amb la presa de Girona- com per mar, prengués els diferents ports i aconseguís el control de la costa. Si no s’hagués pres Roses difícilment haurien pres Girona i Sant Feliu de Guíxols.

A Roses, hem de suposar que el comte es reservà el domini del port mentre l'abat tenia el domini de la vila i l'entorn rural del terme. Així, l'àrea portuària es dividí clarament en dues zones: el barri del Port i el raval de les Botigues. Suposem que la primera zona va estar sota la jurisdicció comtal i la segona sota l'abacial. El control de l'activitat comercial i la fiscalitat (lleuda, ancoratge) ${ }^{24}$ que s'hi exercia estava en mans del comte, i també l'activitat militar, en aquest cas representada per les galeres i la drassana, mentre que l'activitat pesquera, al raval de les Botigues, estava sota control de l'abat i també tot el que tenia relació amb la seva fiscalitat (delme del peix, peix senyoriu i peix de l'obra).

24 A Barcelona, al segle XIII, es cobraven una sèrie d'impostos indirectes, com la lleuda, el passatge i el mesuratge (Ortí 1996, 18). 


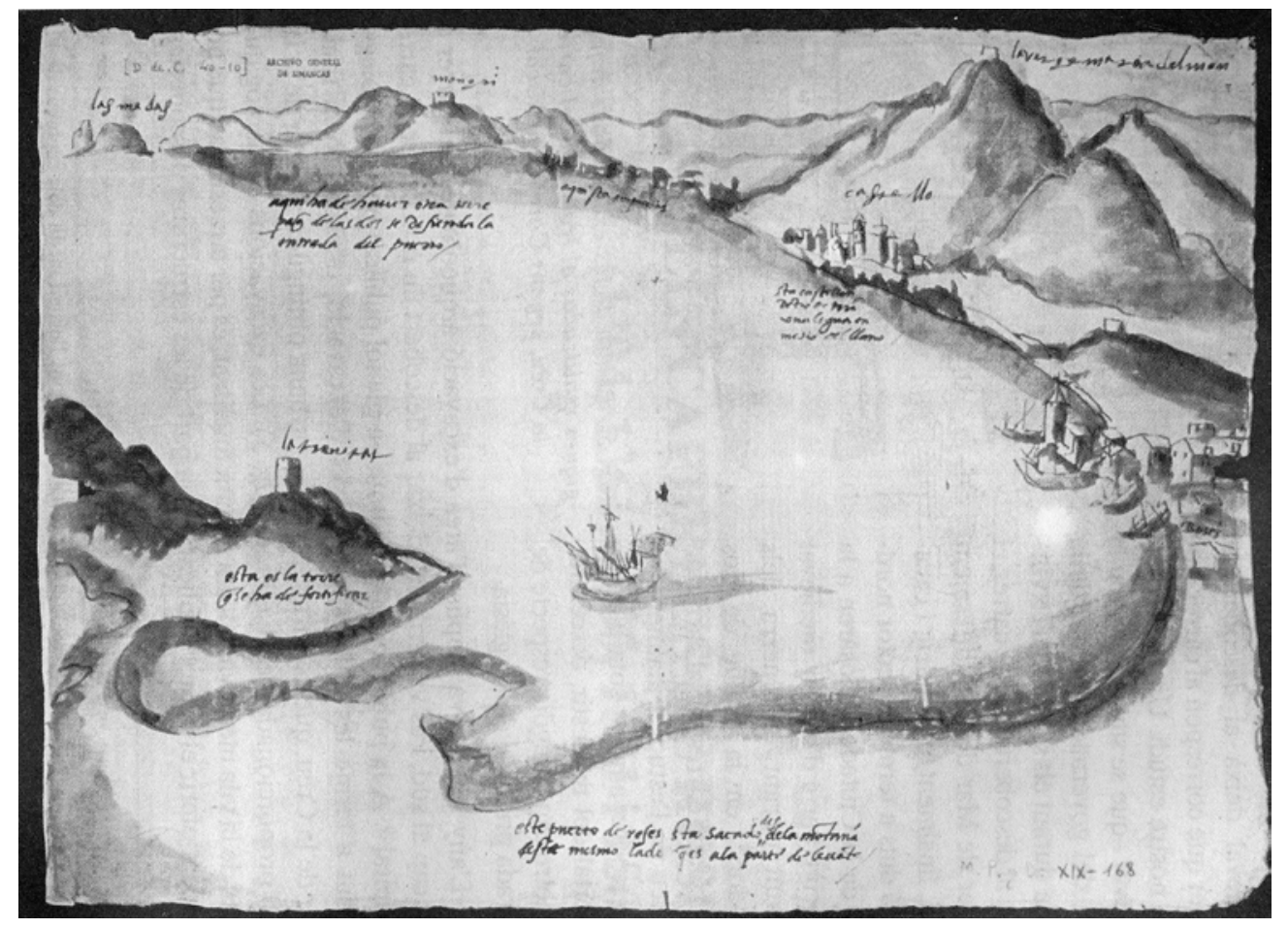

Coneixem prou bé el barri del Port bé gràcies al capbreu de l'any 1500, el qual ens mostra la seva trama urbana, una plaça central davant dels murs de la vila i els portals Nou i de Mar, una plaça que estava flanquejada per cases i magatzems de mercaders, alguns solars buits en espera de ser edificats, i l'antiga drassana comtal reconvertida en la Casa del Consell de la Universitat de Roses. El barri estava protegit pels costats amb uns murs coneguts com l'esperó de llevant i l'esperó de ponent. Aquesta àrea disposava d'un moll i una torre a la seva punta.

La drassana comtal en el seu origen deuria ser un espai que es reservà el comte per construir i tenir emmagatzemades les seves galeres ( $i$ altres efectes navals $i$ armament), per la qual cosa cal suposar que devia tancar-se o delimitar-se amb un mur d'estaques o d'obra. Segurament amb el temps s'hi obriren botigues i al final es construí l'edifici que va permetre guardar la o les galeres sota cobert.

De l'activitat marítima - militar i comercial - del comte a l'alta edat mitjana se n'ha parlat a bastament. El poder naval continuà en el segle XIII, com un dels principals actors en la conquesta de Mallorca i segurament amb la participació mínima d'una galera l'any 1228. A partir d'aquesta data tenim poques notícies. El 1305, una galera comtal pren 65 granadins a la costa andalusa; el 1311, una galera comtal ataca un vaixell venecià, i l'activitat s'esllangueix fins a la venda, el 1325, de l'última galera a Roses per pagar les despeses de casament. De fet la darrera notícia tracta de la venda d'una nau del comte — no pas una galera-, l'any 1335: una nau de dues cobertes, a més de la seva barca de panescalm, la gróndola i armament.
Figura 12. Vista del Golf de Roses, any 1543 (De la Fuente 2016, 186) 
L'any 1359, en un document referent a obres a la muralla, es parla de la drassana («muri sive dressanas cum turri versus mare»), que podria fer referència al tram de mar de la muralla medieval i una de les seves torres, o bé a l'esperó de llevant, allargat pel moll i la torre que hi havia a la seva punta.

És probable que a mitjan segle xiv la drassana comtal estigués fora d'ús. Per aquest motiu, quan Martí l'Humà crea la universitat de Roses, al mateix moment o bé poc després es devia cedir aquest edifici transformant la seva funció militar a una de política i administrativa, o bé el magatzem tingué ús polític i administratiu, i l'espai una utilització comercial. Un cop perduda la seva funció militar i naval, i amb l'avenç de la costa s'urbanitzà l'espai entre la drassana i la línia de costa, construint una línia de cinc cases entre l'antiga drassana i la platja. Aquesta reconversió que també va viure la Drassana Vella de Barcelona i la drassana de Sant Feliu de Guíxols, reconvertides totes dues en un espai comercial.

Hem d'anar en compte, perquè si un edifici és anomenat drassana és que devia acollir almenys una galera. Tenint en compte que una galera sotil al segle XIV feia $40 \mathrm{~m}$ de llargada, aproximadament, per uns $5 \mathrm{~m}$ amplada, l'edifici hauria d'ocupar una superfície d'uns $400 \mathrm{~m}^{2}$. Si l'edifici anomenat drassana és més petit, no podria haver-s'hi construït una galera ni haverl'hi emmagatzemat. Per tant hauríem de concloure que es tractaria d'un magatzem de la drassana, i per tant aquesta ocupava l'espai de la plaça del Port, reconvertida la seva funció militar en comercial, tal com ens indica el capbreu de l'any 1500.

En el cas de Roses, i a diferència dels ports de Barcelona i Sant Feliu de Guíxols, aquest ja disposava de moll a principi del segle xiv. No sabem quan es va construir ni amb quin objectiu. Cal suposar que la seva funció seria protegir les embarcacions de la mala mar i dels enemics, i alhora facilitar la càrrega i descàrrega de mercaderies. Per tant, la seva construcció devia ser, per una banda, iniciativa del comte i, per l'altra, de l'oligarquia mercantil de Castelló d'Empúries. Si bé en el capbreu de l'any 1304 i 1361 es fa referència a l'àrea del port com a «portu» - l'existència d'un moll i d'una torre a la seva punta data de l'any 1311 (Palou 1992) - hi ha la possibilitat que el document de l'any 1389 que fa referència a «omnes merlets turrium del port murarum de Rosis» tingui relació amb la torre del moll (o bé amb les torres del tram de mar de la muralla). Tot i les referències més o menys ambigües, el moll i la torre s'aprecien clarament tant en el dibuix del Golf de Roses (fig. 12) com en el plànol del primer projecte de fortificació de Pizaño, tots dos de l'any 1543.

En una superposició d'aquest plànol amb un mapa actual de Roses (fig. 14), la torre i el moll quedarien fora del recinte emmurallat del segle XVI, sota del passeig i jardí que hi ha al tram de mar, quedant la torre just a sota de l'avinguda d'entrada a Roses. La distància entre el tram de mar de la muralla medieval i la torre del moll era de $80 \mathrm{~m}$, mentre que avui en dia la línia de costa ha avançat respecte a la que existia a primera meitat del segle Xvi en $120 \mathrm{~m}$. 


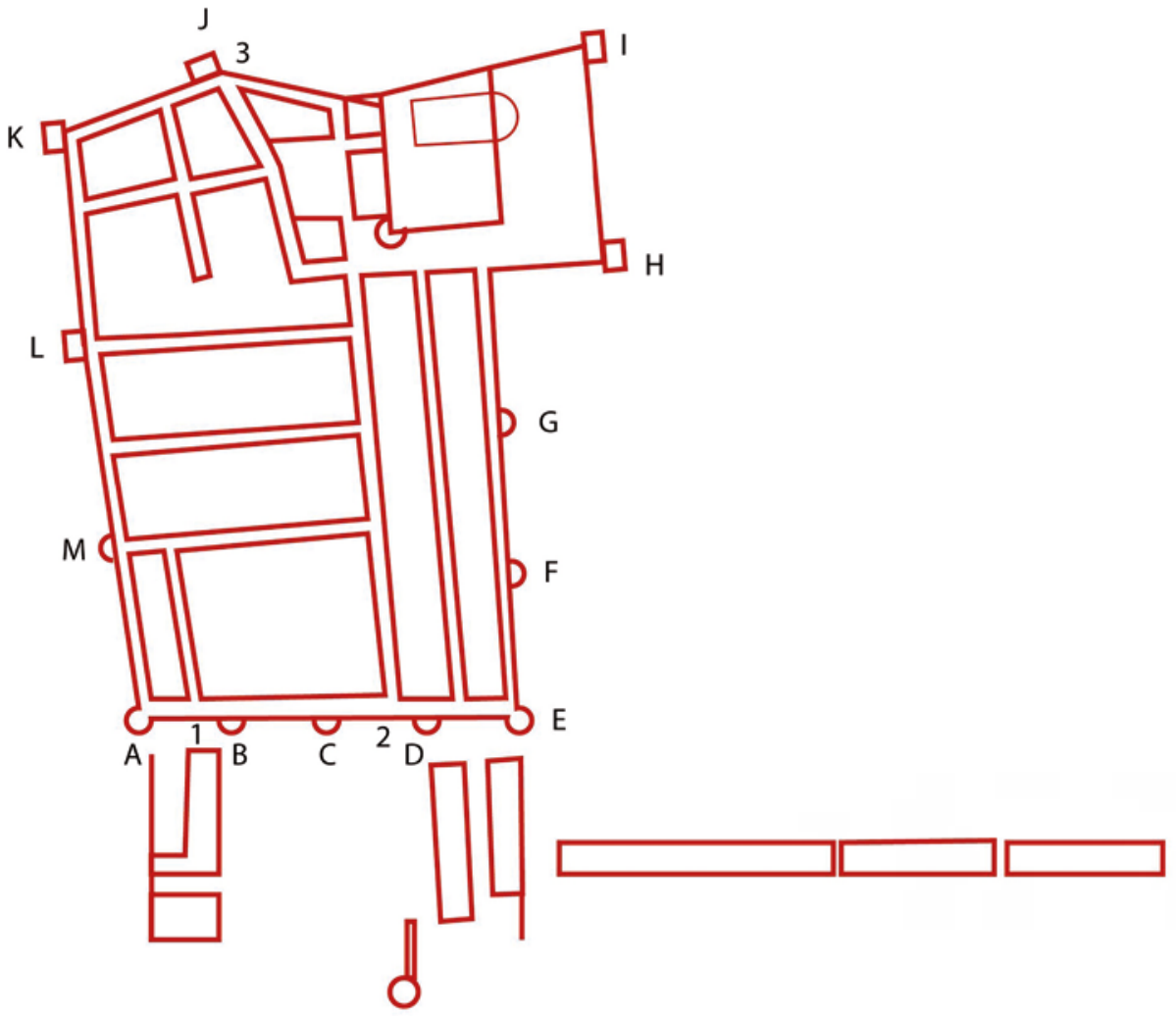

Figura 13. Trama urbana

de la vila de Roses,

segons el capbreu de l'any $1500(\mathrm{MPH})$.

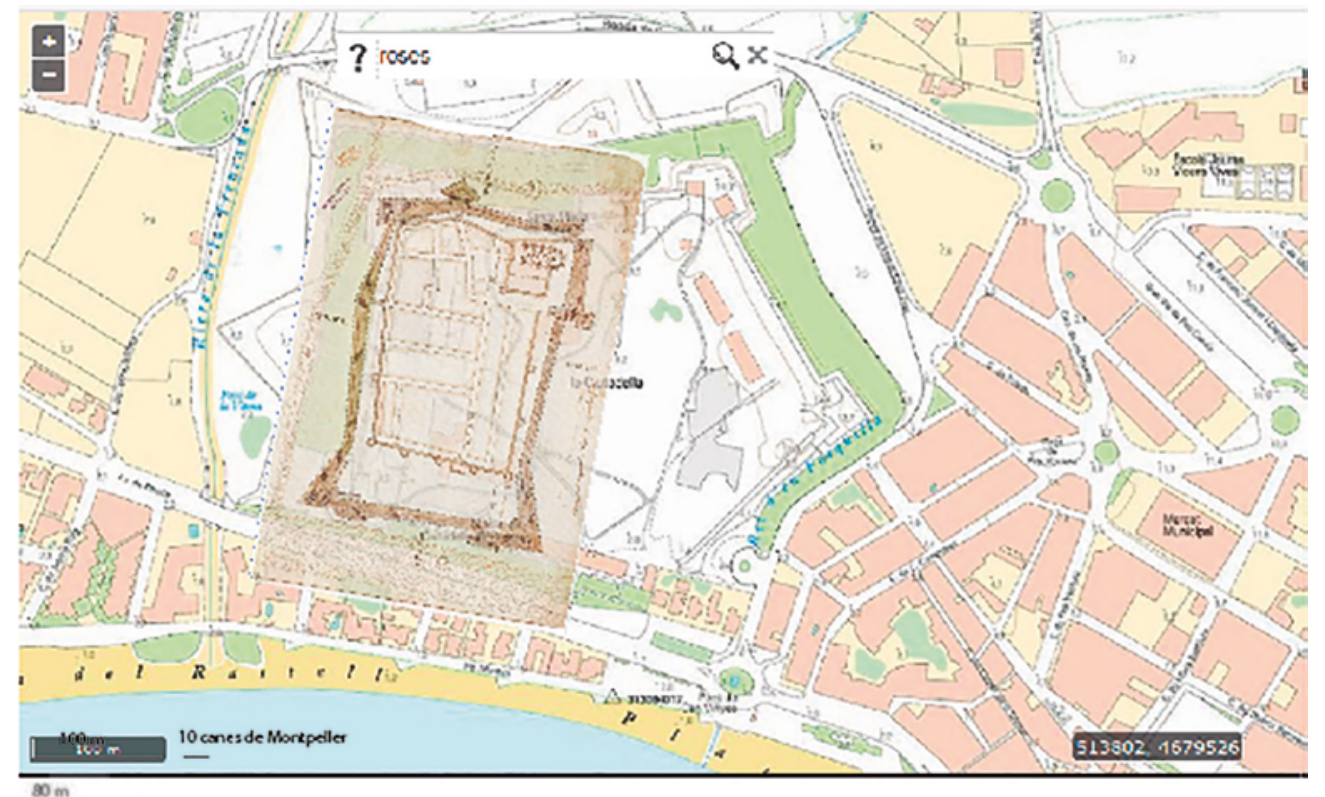

Figura 14. Superposició plànols del primer projecte de Pizaño, any 1543, sobre plànol actual de Roses (MPH). 
En el dibuix del golf de Roses de l'any 1543 l'autor ens assenyala la presència de les barraques de pescadors del raval de les Botigues. Sabem, segons el capbreu de l'any 1500, que hi havia 32 botigues de pescadors i tres de mestres d'aixa. Augmentaren a 35 botigues l'any 1543. En aquest mateix dibuix hi veiem una gran nau ancorada, indicadora del lloc on fondejaven les naus en cas de temporal, en espera que millorés i poder passar el cap de Creus, o bé fent temps per acostarse al moll per carregar o descarregar. I més a l'esquerra, inevitablement, la torre. En el dibuix de 1543 se l'anomena «la trinitat», i a sota s'afegeix: «esta es la torre que se ha de fortificar». De fet, en el projecte de construcció del castell de la Trinitat, de Pizaño, s'hi pot arribar a veure la torre medieval, integrada al seu interior i anomenada com «tore vieja». De la torre medieval de la Trinitat, l'única referència documental coneguda data de l'any 1508, quan es demana refer de nou la capella de la Santíssima Trinitat, amb el seu altar, retaule i objectes per dir missa, a la torre o far de la punta del Morrell de Roses. Aquest edifici compliria les funcions habituals, de vigilància, protecció, far, transmissió de comunicacions de dia i de nit, element dissuasiu, etc., i a més, en el cas de Roses, tindria una funció religiosa. Afegim que també podria haver estat un lloc ideal per detectar l'arribada dels grans bancs de peix blau (tonyina, bonítol i melva) al golf de Roses, i donar-ne avís als pescadors rosincs, que, per pescar-los, armaven un art collectiu conegut com a cinta i que calaven a partir de la punta del Morrell en direcció a la cala de Canyelles (Pujol 2014, 101-104).

La funció del port de Roses en el sistema portuari català va anar variant durant tota l'edat mitjana, molt marcada per la seva vinculació amb l'Empordà i el comtat d'Empúries, des del punt de vista de l'hinterland terrestre, i amb el cap de Creus des del punt de vista marítim. En un inici fou port pesquer, que esdevingué militar i comercial per la seva funció de port comtal a partir de mitjan segle XI. El seu paper en les xarxes marítimes fou el del principal port de refugi i escala al sud del cap de Creus, però des del punt de vista comercial (i fiscal) la seva activitat anà minvant a partir del segle XIv, tot i ser encara un dels pocs ports catalans habilitats com a ports carregadors i descarregadors i un dels pocs que disposava d'un moll. La seva activitat comercial li va permetre disposar fins i tot de cònsols de mar, que exercien la seva funció judicial en els conflictes marítims, segons es documenta l'any 1545 (Raurich 2000). ${ }^{25}$

\section{EN CONCLUSIÓ}

Tot port existeix gràcies als condicionants geomorfològics i geogràfics, i pot estar dotat de més o menys infraestructures portuàries que ajuden a completar-ne les mancances i/o augmentar-ne la potencialitat funcional. Aquest port, a més, s'integra en una xarxa de comunicació terrestre i marítima en la qual tindrà un

25 No sabem a partir de quin moment va obtenir privilegi de tenir Consolat de Mar: probablement a la segona meitat del segle XV. En el cas de Sant Feliu de Guíxols se li va concedir el 1442, i Barcelona ja en tenia des del 1279 (Ferrer 1999). 
paper més o menys important, per la seva situació i funció en el sistema portuari a què pertany. En el cas català és evident que Barcelona era el port principal, de la mateixa manera que Gènova, Pisa i Venècia disposaven dels seus propis sistemes portuaris i xarxes comercials. La realitat és que totes aquestes xarxes s'entrecreuaven, utilitzant alguns ports com a nodes de connexió. A Catalunya existien diverses xarxes: una de cabotatge a la Costa de Llevant i una altra a la de Ponent, que convergien a Barcelona, si bé es podien allargar cadascuna cap al nord i cap al sud; una altra xarxa que enllaçava amb els principals ports de la Corona d'Aragó, Llenguadoc i Provença; una tercera xarxa que abastava bona part dels ports de tota la Mediterrània Occidental, des de Sicília fins a Tunis per l'est i l'Estret de Gibraltar a l'oest; i finalment les grans rutes de Llevant i Flandes, que duien per una banda cap a Constantinoble, Rodes, Beirut i Alexandria, i per l'altra per l'Atlàntic cap a Southampton i Bruges. A Barcelona convergien totes les xarxes comercials del sistema portuari català, mentre que Sant Feliu de Guíxols actuà des del segle xiI com a port complementari al de Barcelona, més que no pas com a port secundari. En canvi, Roses formava part d'una xarxa d'àmbit més reduït des del punt de vista comercial, sobretot a partir del segle XIV, tot i seguir mantenint-se com un port d'escala i refugi d'altres xarxes.

\section{BIBLIOGRAFIA}

AIRALDI, G. 2012, Genoa and Barcelona, GERWAGEN, R, Shipping, Trade and Crusade in the Medieval Mediterranean. Studies in Honour of John Pryor, Londres: Routledge, 223-229.

BALAÑÀ I ABADIA, P. 1981, Les destruccions de l'Empúries medieval i la capitalitat comtal, Annals de l'Institut d'Estudis Empordanesos, 15, 126-135.

BANKS, P. 1992, Lestructura urbana de Barcelona, 714-300, Història de Barcelona. La formació de la Barcelona medieval, Barcelona: Enciclopèdia Catalana-Ajuntament de Barcelona.

BANKS, Phillip 2003, El creixement físic de Barcelona, segles X-XIII, Quaderns d'Història, 8, 11-33.

BATLLE PRATS, LL. 1968, Censo y población de Sant Feliu de Guíxols en 1360, Miscelánea de estudios dedicados a Martínez Ferrando, ANBAyA, 43-52.

BENSCH, S.P. 2000, Barcelona i els seus dirigents (1096-1291), Barcelona: ProaAjuntament de Barcelona.

CABESTANY I FORT, J.F., SOBREQUÉS I CALLICÓ, J. 1972, La construcció del port de Barcelona al segle XV, Cuadernos de Historia Económica de Cataluña, 7, 41-114.

CAPMANY Y DE MONTPALAU, A. de 1961-1963, Memórias históricas sobre la marina, comercio y artes de la antigua ciudad de Barcelona, 4 vols., Madrid, 1779-1792. Reedició anotada i revisada per E. Giralt i Raventós i C. Batlle i Gallart, Barcelona, 3 vols. 
CARRÈRE, C. 1977, Barcelona 1380-1462. Un centre econòmic en època de crisi, Barcelona: Curial (Documents de cultura, 11), 2 vols. Traduit per Hermínia Grau de Duran, Barcelone, centre économique à l'époque des difficultés (13801462), Paris-La Haye: Mouton.

COSTA, Ma.M. 1981, Palamós medieval: aspectes de la defensa de la vila, Estudis del Baix Empordà, 1, 139-154.

COSTA, M. 1988, Reparació d'una nau en el port de Palamós (1434), Estudis del Baix Empordà, 7, 87-100.

CRUSELLES, E. 2007, El puerto de Valencia en el Mediterráneo medieval (siglos XIII-XV), HERMOSILLA, J. (coord.), Historia del puerto de Valencia, València, 63-125.

CUADRADA, C., ORLANDI, A. 1994, Ports, tràfics, vaixells, productes: italians i catalans a la Mediterrània baixmedieval, Anuario de Estudios Medievales, 24, 3-48.

CUBELES I BONET, A., PUIG I VERDAGUER, F. 2003, La Drassana i la gestació de la façana marítima de Barcelona, Drassana, 11, 50-61.

CUBELES I BONET, A. 2003, Poder i llançament urbanístic en el segle XIV, Barcelona. Quaderns d'Història, 8, 35-64.

CUBELES I BONET, A. 2011, Noves dades, noves perspectives i nous objectius en l'estudi històric de la Drassana Reial de Barcelona, Drassana, 19, 120-136.

CUBELES I BONET, A. 2014, La Drassana de la Ciutat i la nova Drassana Reial als segles XIII i XIV, Barcelona. Quaderns d'Història, 21, 79-94.

DIAZ BORRÀS, A., PONS I PONS, A., SERNA ALONSO, J. 1986, La construcción del puerto de Valencia: problemas y métodos (1283-1880), València.

DIAZ BORRÀS, A., PONS I PONS, A., SERNA ALONSO, J. 1990-1991, El primer intento integral de dotación portuária en Valencia durante la Era de los Descubrimientos: razones de un fracaso (1480-1520), Anual de la Universidad de Alicante. Departamento de historia medieval, 8, 169-185.

DIAZ BORRÀS, A., PONS I PONS, A., SERNA ALONSO, Just 1995, Apunts sobre la problemàtica del port medieval de València, Drassana, 3, 2632.

ESTRADA-RIUS, A. 2004, La Drassana Reial de Barcelona a l'edat mitjana. Organització institucional $i$ construcció naval a la Corona d'Aragó, Barcelona: Museu Marítim.

ESTRADA-RIUS, A. 2008, La Generalitat de Catalunya a la Drassana Reial de Barcelona en temps d'Alfons el Magnànim, Barcelona: Museu Marítim, Barcelona.

FERRER I MALLOL, M.T. 1999, El consolat de mar i els consolats d'ultramar, instrument i manifestació de l'expansió del comerç català, L'expansió catalana a la Mediterrània a la Baixa Edat Mitjana, Barcelona: CSIC, 53-79. 
FERRER I MALLOL, M.T. 2007, Navegació, ports i comerç a la Mediterrània a la Baixa Edat Mitjana, BALLESTER PÉREZ, J., BALLESTER PASCUAL, G. (eds.), Comercio, redistribución y fondeaderos. La navegación a vela en el Mediterráneo. Actas de las $V$ Jornadas Internacionales de Arqueología Subacuática, València.

FOSSATI, C. (ed.) 2007, Genovesi e Catalani: guerra sul mare. Relazione di Antonio Gallo (1466), Genova: Memorie Genovesi/Fratelli Frilli.

GARCIA ESPUCHE, A. 2007, Espais urbans de la gent de mar. Barcelona segles XIV a XVIII, Drassana, 15, 36-53.

GILABERT TOMÀS, J. 2008, Port Fangós i l'expansió mediterrània de la Corona d'Aragó, Recerca, 12, 243-280.

GUILlerÉ, C., PINTO, A. 2005, Le port de Sant Feliu de Guíxols et l'expansion catalane (1340-fin du XV siècle), NARBONA VIZCAÍNO, R. (ed.), XVIII Congrès d'Història de la Corona d'Aragó. València, 2004, 9-14 setembre, , vol. 2, 1.233-1.248.

HINOJOSA, J. 1989, Ciudades portuarias en la Corona de Aragón durante la baja edad media: los ejemplos de Mallorca, Valencia y Alicante, POLEGGI, E. (ed.), Città portuali del Mediterraneo. Storia e archeologia. Atti del Convegno Internazionale di Genova, Gènova, 151-165.

HINOJOSA, J. 1996, Ciudades portuarias y puertos sin ciudades a fines de la Edad Media en el Mediterráneo occidental, Tecnología y sociedad. Las grandes obras públicas en la Europa medieval, Pamplona, 263-287.

HORN, H. J. 1989, Jan Cornelisz Vermeyen, Painter of Charles V and his conquest of Tunis, Doornspijk: Davaco Publishers.

IGLÈSIES FORT, J. 1962, El fogaje de 1365-1370. Contribución al conocimiento de la población de Cataluña en la segunda mitad del siglo XIV, Memorias de la Real Academia de Ciencias y Artes de Barcelona, 34, 249-356.

IGLÈSIES, J. 1991, El fogatge de 1497. Estudi i transcripció, Barcelona: Fundació Salvador Vives i Casajuana — Rafael Dalmau, 2 vols.

IGUAL LUIS, D. 2014, "Non ha porto alcuno, ma sola spiaggia". La actividad marítima valenciana en el siglo XV, Aragón en la Edad Media, 25, 101-134.

JULIÀ BRUGUÉS, R., RIERA MORA, S. 2014, Evolució geomorfològica del barri de la Ribera en èpoques històriques, Quarbis: Quaderns d'Arqueologia $i$ Història de la Ciutat de Barcelona, 10, 70-93.

LADERO QUESADA, M.A. 1989, Puertos de Andalucía en la baja Edad Media: Sevilla y Málaga, POLEGGI, E. (ed.), Città portuali del Mediterraneo. Storia e archeologia. Atti del Convegno Internazionale di Genova, Gènova, 133140.

MADURELL I MARIMÓN, J.M. 1970, Les obres del port i de les fortificacions de Palamós (1517-1726). Contribució a la seva història, Annals de l'Institut d'Estudis Gironins, 20, 75-104. 
MARTÍNEZ LATORRE, D. 2004, La fortificación de Barcelona a mediados del siglo XVI. El baluarte de las Atarazanas y la Puerta de Mar de Giovan Battista Calvi, Drassana, 12, 83-92.

MORENO, I., NADAL, E. 2015, La Reial drassana de Barcelona: de l'apogeu medieval al fals declivi en época moderna, VILA, J.M. (ed.), $V$ Congrés d'Arqueologia medieval $i$ moderna a Catalunya. Actes. Vol. I. Intervencions arqueologiques 2010-2014: La ciutat, Barcelona: Ajuntament de Barcelona, 575-590.

MUTGÉ, J. 2004, Les Drassanes de Barcelona en temps d'Alfons el Benigne i de Pere el Cerimoniós, Política, urbanismo y vida ciudadana en la Barcelona del siglo XIV, Barcelona: CSIC, 183-186.

ORTÍ I GOST, P. 1996, La construcció del sistema fiscal municipal a Barcelona, segles XIII-XIV, Barcelona. Quaderns d'Història, 2/3, 17-34.

ORTÍ I GOST, P. 2000, Renda i fiscalitat en una ciutat medieval: Barcelona, segles XII-XIV, Barcelona: CSIC.

ORVIETANI BUSCH, S. 2001, Medieval Mediterranean Ports. The Catalans and Tuscan Coasts, 1100 to 1235, Leiden: Brill.

PALOU I MIQUEL, H. 1992, Ports i drassanes, Catalunya a l'època de Colom (1450-1506), Barcelona, 96-98.

PERE III EL CERIMONIÓS 1995, Crònica, a cura d'Anna Cortadellas, Barcelona: Edicions 62 (MOLC, 113).

PONS GURI, J.M. 2005, Uns franqueses per a la vila i el port de Blanes, Acta Historica et Archaeologica Mediaevalia, 26, 263-270.

PUJOL I HAMELINK, M. 1993, Roses, el port del comtat d'Empúries, Programa de Festa Major, Roses, 13-16.

PUJOL I HAMELINK, M. 1997, La vila de Roses (segles XIV-XVI). Aproximació a l'urbanisme, la societat i l'economia a partir dels capbreus del monestir de Santa Maria de Roses (1304-1565), Figueres: Brau-Ajuntament de Roses.

PUJOL I HAMELINK, M. 2008, Tecnología marítima en la Corona de Aragón: construcción naval, navegación e infraestructuras portuarias, NAVASCUÉS PALACIO, P., Ars Mechanicae. Ingeniería medieval en España, Madrid: Cedex Ministerio de Fomento / Fundación Juanelo Turriano, 151-166.

PUJOL I HAMELINK, M. 2014, Un mar de conflictes. La pesca a Roses durant l'Antic Règim, 1592-1835. Tecnologia, economia i societat en la costa del Golf de Roses i el Cap de Creus, Roses: Ajuntament de Roses.

PUJOL I HAMELINK, M. 2018a, La marina catalana a la Baixa Edat Mitjana. Sant Feliu de Guixols, un port excepcional en la construcció $i$ carenat de coques, naus i naus grosses, Barcelona: Diputació de Barcelona.

PUJOL I HAMELINK, M. 2018b, Lurbanisme de la vila de Roses (segles XIXVIII): la complementarietat de les fonts d'informació, Rodis, 1, 69-92. 
PUJOL I TUBAU, P. (ed.) 1921, Crònica del racional de la ciutat (1334-1417), Recull de documents i estudis, 1, Barcelona: Arxiu Municipal.

RAURICH I SANTALÓ, X. 2000, Mariners contra patró: un arbitratge entre genovesos, a Roses (1545), Annals de l'Institut d'Estudis Empordanesos, 33, 97-115.

RIERA I MELIS, A. 1995, Les Drassanes Reials de Barcelona a la baixa edat mitjana, Drassana, 3, 4-8.

RIERA VIADER, S. 2005, La construcció del port de Barcelona durant el regnat de Ferran II el Catòlic, XVIII Congrés d'Història de la Corona d'Aragó, València, vol. II, 1.417-1.425.

SALICRÚ I LLUCH, R. 2003, En lo port de Cochliure o en la plaja de Canet?, El Món Urbà a la Corona d'Aragó, del 1137 als decrets de Nova Planta XVIII Congrés d'Història de la Corona d'Aragó, Barcelona: Universitat de Barcelona — Universitat de Lleida, vol. I, 573-594.

SANS TRAVÉ, J.M. (dir.) 1994, Dietaris de la Generalitat de Catalunya, Barcelona.

SANS TRAVÉ, J.M. (ed.) 1992, Dietari o Llibre de Jornades (1411-1484) de Jaume Safont, Barcelona: Fundació Noguera.

SCHWARTZ LUNA, F., CARRERAS CANDI, F. (eds.) 1892, Manual de Novells Ardits vulgarment apellat Dietari del Antich Consell Barceloni, Barcelona: Henrich y Cia., vol. I (1390-1446).

SIMBULA, P.F. 2009, I porti del Mediterraneo in età medievale, Milà: Bruno Mondadori.

SMITH, R.S. 1933, Documentos del Consulado de Mar de Girona y en San Feliu de Guíxols, Revista Jurídica Catalana, XXXIV, 128-132.

SOBERÓN RODRÍGUEZ, M. 2010, El port baixmedieval de la ciutat de Barcelona: una visió des de l'arqueologia. L'escullera de 1477 i la troballa d'un vaixell tinglat, Quarbis. Quaderns d'Arqueologia i Història de la Ciutat de Barcelona, 6, 134-163.

SOBERÓN RODRÍGUEZ, M. 2012, "Que en ell stara segura la maior nau del mon”. Tràfic i evolució del port de Barcelona al segle XV, Quarhis. Quaderns d'Arqueologia i Història de la Ciutat de Barcelona, 8, 54-78.

SOBERÓN RODRÍGUEZ, M. 2014, Caixes i pontons. Els aspectes tècnics en la construcció del primer port medieval de Barcelona, 1439-1455, Barcelona. Quaderns d'Història, 21, 125-138.

SOLDEVILA, F. 2007, Les quatre grans Cròniques. I. Llibre dels fets del rei en Jaume, revisió filològica de Jordi Bruguera i revisió històrica de Maria Teresa Ferrer i Mallol, Barcelona: IEC.

SOLDEVILA, F. 2008, Les quatre grans Cròniques. II. Crònica de Bernat Desclot, revisió filològica de Jordi Bruguera i revisió històrica de Maria Teresa Ferrer i Mallol, Barcelona: IEC. 
SOLDEVILA, F. 2011, Les quatre grans Cròniques. III. Crònica de Ramon Muntaner, revisió filològica de Jordi Bruguera i revisió històrica de Maria Teresa Ferrer i Mallol, Barcelona: IEC.

SOLDEVILA, F. 2014, Les quatre grans Cròniques. IV. Crònica de Pere el Cerimoniós, revisió filològica de Jordi Bruguera, revisió històrica de Maria Teresa Ferrer i Mallol, Barcelona: IEC.

TINTÓ, M. 1992, Ordinacions dels barquers de la ciutat de Barcelona durant el segle XV, Acta Medievalia, 10, 413-424.

VIVO, J. 2005, Quatre anys al port: la construcció del primer moll de Sant Feliu de Guíxols (1591-1594), Estudis del Baix Empordà, 24, 55-68. 